\title{
Would Stronger Seat Belt Laws Reduce Motor Vehicle Crash Deaths? A Semi-Bayesian Analysis
}

\author{
Sam Harper ${ }^{1,2,3}$ \\ ${ }^{1}$ Epidemiology, Biostatistics \& Occupational Health, McGill University \\ ${ }^{2}$ Institute for Health and Social Policy, McGill University \\ ${ }^{3}$ Centre for Population Dynamics, McGill University
}

2019-03-21

This article has been accepted for publication in Epidemiology (2019) following peer review, and the Version of Record can be accessed online at http://dx.doi.org/10.1097/EDE.0000000000000990

\begin{abstract}
Background: For policy questions where substantial empirical background information exists, conventional frequentist policy analysis is hard to justify. Bayesian analysis quantitatively incorporates prior knowledge, but is not often used in applied policy analysis. Methods: We combined 2000-2016 data from the Fatal Analysis Reporting System with priors based on past empirical studies and policy documents to study the impact of mandatory seat belt laws on traffic fatalities. We used a Bayesian data augmentation approach to combine information from prior studies with difference-in-differences analyses of recent law changes to provide updated evidence on the impact that upgrading to primary enforcement of seat belt laws has on fatalities. Results: After incorporating the evidence from past studies, we find limited evidence to support the hypothesis that recent policy upgrades affect fatality rates. We estimate that upgrading to primary enforcement reduced fatality rates by 0.37 deaths per billion vehicle miles traveled (95\% posterior interval $-0.90,0.16)$, or a rate ratio of 0.96 (95\% posterior interval $0.91,1.02)$, and increased the proportion of decedents reported as wearing seat belts by 7 percentage points (95\% posterior interval 5, 8), or a risk ratio of 1.18 (95\% posterior interval 1.13, 1.24). Conclusion: Bayesian methods can provide credible estimates of future policy impacts, especially for policy questions that occur in dynamic environments, such as traffic safety.
\end{abstract}




\section{Introduction}

Despite long-term progress in reducing deaths from motor vehicle crashes in the United States, there remains substantial room for improvement. The US still registers more than 30,000 deaths and 2 million non-fatal injuries annually, and motor vehicle crashes remain a leading cause of death for young people. Moreover, the United States lags behind many other rich countries in measures of traffic safety. A recent comparison [1] found the US had the highest traffic crash death rate per 100,000 population among 20 high-income (as defined by the World Bank) country members of the Organization of Economic Co-operation and Development, and ranked 18th of 20 in terms of observer-reported seat belt use.

The poor international ranking and substantial ongoing burden of crash-related injuries and deaths in the US has prompted a number of calls to implement stronger safety legislation [1]. A good deal of safety legislation is enacted at the state level, and states have a number of potential policy options. A recent report by the RAND organization [2] and a tool [3] developed by RAND for the US Centers for Disease Control and Prevention (CDC) provide detailed cost-effectiveness estimates for range of policies such as increasing sobriety checkpoints, automated speed-trap and red-light cameras, and higher fines for not wearing seat belts.

One policy that is routinely encouraged [4] and considered cost-effective [2] is primary enforcement of mandatory seat belt laws. Primary enforcement means drivers and passengers may be ticketed directly for not using seat belts, rather than being additionally cited after another traffic violation (i.e., secondary enforcement). The RAND report and the CDC's Motor Vehicle Prioritizing Interventions and Cost Calculator for States presently use estimates for the effectiveness of upgrading seat belt laws to primary enforcement based on studies conducted in the 1980s and 1990s. In light of past findings, both the CDC and the National Highway Transportation Safety Association have emphasized the need for all states with secondary laws to upgrade to primary enforcement.

Currently, for adults 35 states and the District of Columbia have a law with primary enforcement and 15 states have secondary enforcement (New Hampshire currently has no law covering adults, see eFigure 1). A number of states may be considering passing legislation to upgrade their mandatory seat belt laws from secondary to primary enforcement. Since the last rigorous studies of primary enforcement upgrades were conducted in the early 2000s [5,6], another 16 states have upgraded their laws to primary enforcement, which provides an opportunity to revise estimates of their impact.

A typical frequentist policy analysis would take advantage of the recent changes in state laws to estimate their impact on crash deaths. However, it seems odd to adopt a purely frequentist stance when considering the question of whether states with secondary enforcement laws should upgrade to primary enforcement. A frequentist analysis takes no account of background information and would thus consider it equally likely that upgrading to primary enforcement decreases death rates by a factor of 100 or 10, or that upgrading actually increases death rates by a factor 10 or 100 . This is empirically absurd, given what is already known from prior studies about how primary enforcement affects crash deaths. We used Bayesian methods to combine prior information about the effect of upgrading with a difference-in-differences analyses of recent law changes to provide updated evidence on the impact that upgrading to primary enforcement has on motor vehicle crash deaths.

\section{Methods}

\section{Prior evidence}

To incorporate prior information on the impact of seat belt law upgrades on fatalities, we reviewed prior empirical studies (see eAppendix for study details), paying particular attention to those cited as strong evidence for upgrading to primary enforcement $[1,4,7-9]$. Most of these studies have focused on two outcomes: fatality rates per vehicle mile traveled, and the proportion of fatalities wearing seat belts.

A key challenge in estimating the impact of primary enforcement upgrades is the non-random nature of policy adoption. For this reason we prioritized studies that used a credible design for estimating our 
parameter of interest, typically an interrupted time series with an unaffected control group [10], or a difference-in-differences design $[11,12]$ that took advantage of multiple policy changes.

To inform our empirical priors we used three studies of primary law upgrades [13-15] that estimated the impact on fatality rates per vehicle mile traveled, and one report [16] of six separate studies on the proportion of fatal occupants wearing seat belts. We took these estimates and conducted random effects meta-analyses [17], which treat each study as a separate estimate and combine them into an average effect estimate, assuming that the studies are sampled from a distribution of possible studies. We tested for heterogeneity across studies using Cochran's $Q$ statistic [18] and used 95\% prediction intervals to estimate the expected range of effect sizes for a new study [17].

eFigure 2 shows forest plots of prior studies for the impact on fatality rates. The average estimate for fatality rates is 0.5 fewer deaths per billion vehicle mile traveled (roughly 1500 deaths per year), with a $95 \%$ confidence interval of (-0.7 to -0.3$)$, and there is not enough evidence to reject the assumption of homogeneity in the effects $Q=1.78,(d f=2), p=0.411$. On the rate ratio scale the average estimate is $0.95(0.93,0.97)$, again with little evidence against homogeneity across studies. eFigure 3 shows the average estimate for the proportion of deaths wearing seat belts and implies that upgrading to primary enforcement increases the proportion of fatal occupants wearing seat belts by 13 percentage points $(95 \%$ CI: 10 to 16$)$. However, there is evidence of between-study heterogeneity $Q=21.18,(d f=5), p=0.001$.

\section{Construction of priors}

We constructed three priors for the effect (rate ratio) of upgrading for each of our outcomes: non-informative, empirical, and subjective. A "non-informative" prior provides minimal information, akin to a frequentist analysis, which we implemented as a lognormal distribution centered at 0 (i.e., a rate ratio of 1) with a large variance: $N(\ln (1), 100)$. We used $95 \%$ prediction intervals from the meta-analysis results to inform our empirical priors, accounting for the uncertainty within and between prior studies $[17,19]$. For mortality we take as plausible priors the $95 \%$ limits of the prediction interval, representing a $95 \%$ chance that the true $R R$ lies between 0.83 and 1.09. This leads to a prior centered at

$\beta_{\text {prior }}=\frac{\ln (0.83)+\ln (1.09)}{2}=\ln (0.95)=-0.05$ with a prior variance of $v_{\text {prior }}=\left[\frac{|\ln (0.83)-\ln (1.09)|}{2 \cdot 1.96}\right]^{2}=0.005$, i.e., $N(\ln (0.95), 0.005)$. For the proportion belted we used the same non-informative prior. The meta-analysis estimate of the increase in proportion belted due to primary enforcement was 0.13 , with a prediction interval of 0.03 to 0.23 . Using a base rate of $40 \%$ of belted deaths in our sample, this translates into a risk ratio of 1.30 with limits of 1.08 and 1.58. We therefore used an empirical prior of $N(\ln (1.30), 0.009)$, which translates into a $95 \%$ chance that the true parameter lies between an $8 \%$ and a $58 \%$ increase in the proportion of deaths wearing seat belts.

Finally, we also used subjective priors based on claims about the magnitude of primary enforcement laws in the policy literature $[3,4]$. Estimates quoted for the impact of upgrading from secondary to primary enforcement are around 7-8\% on fatalities, and 12 to 18 percentage points on seat belt use. We added some additional uncertainty to these estimates and used 0.8 and 1.0 as plausible priors for the $R R$ of primary vs. secondary on mortality to generate a lognormal prior of $N(\ln (0.90), 0.003)$. For the proportion belted the estimates of 12 to 18 percentage point increases correspond to approximate risk ratios of 1.3 and 1.45 . We added some additional uncertainty to these estimates to derive a subjective prior based on a $95 \%$ chance that the true $R R$ lies between 1.15 and 1.60 , implemented as a lognormal prior $N(\ln (1.36), 0.007)$.

\section{Data}

This study used de-identified data and did not require ethics review. We obtained person-level data on fatal crashes among drivers and passengers from the Fatal Analysis Reporting System [20] for the years 2000-2016. We gathered information on the date and type (secondary or primary enforcement) of mandatory seat belt policies from the Insurance Institute for Highway Safety [21]. We included all states except New Hampshire, which is the only state without a mandatory seat belt law covering adults. We 
aggregated the person-level crash data by state, age group, and year of crash, and we used the effective date of each law to calculate the proportion of months in a given year a state had a primary law in effect (effective dates are given in eTable 1).

Crash risk strongly increases with the amount of driving. To account for travel exposure we calculated annual estimates of state-specific vehicle miles traveled from the Fatal Analysis Reporting System website [22], which provides the number of fatalities and the fatality rate per 100 million vehicle miles traveled annually for each state from 2000-2016. Estimates travel exposure were not available by age at the state level. To control for potential confounding by other policies we also obtained time-varying data on laws pertaining to maximum speed limits, legal limits for blood alcohol concentration, and graduated driver's license programs [23], and, additionally, annual state police per capita (2000-2015) as a proxy for traffic safety enforcement [24], state average alcohol consumption from 2000-2015 [25], and annual state median household income (constant dollars) from the US Census [26]. Police per capita and alcohol consumption were linearly extrapolated to 2016 from 2000-2015 data.

\section{Statistical Methods}

\section{Models for likelihood}

Similar to prior studies, we used a difference-in-differences design $[11,12]$ to estimate the effects of upgrading to primary enforcement. That is, we compared the difference in the outcome before and after upgrading to primary enforcement among states that upgraded with the difference in the outcome among states that did not upgrade their laws during the same period. We implemented this using Poisson regression to model the number of crash deaths with the state-year-specific estimate of vehicle miles traveled as the offset. We assume the number of fatalities in age group $a$ in state $s$ at time $t$ is conditionally Poisson, i.e., $y_{\text {ast }} \sim \operatorname{Poisson}\left(\mu_{\text {ast }}\right)$ :

$$
\ln \left(\mu_{a s t}\right)=\alpha+\beta \times \text { Primary }_{s t}+\boldsymbol{\gamma} \mathbf{A}_{a s t}+\delta \mathbf{Z}_{s t}+\boldsymbol{\sigma}_{s}+\boldsymbol{\tau}_{t}+\ln \left(V M T_{s t}\right)
$$

where $\beta$ is our coefficient of interest (Primary $=1$ when a primary enforcement law is in effect in state $s$ at time $t$ ), and $\gamma, \delta, \sigma$, and $\boldsymbol{\tau}$ represent vectors of coefficients for age groups, other time-varying state covariates, state fixed effects, and year fixed effects, respectively. State fixed effects control for any time-constant unobserved differences across states that may also be correlated with death rates. Year fixed effects flexibly control for any unmeasured factors that may be affecting death rates in all states.

To estimate the effect on the proportion of belted fatalities we used a grouped logistic regression model since we have-for each age group, state, and year-the number of all fatalities where decedents were not wearing seat belts as well as the total number of fatalities, so we modeled the proportion $p_{a s t}$ of all fatalities $n_{\text {ast }}$ where occupants were wearing seat belts:

$$
\ln \left(p_{\text {ast }} /\left[1-p_{\text {ast }}\right]\right)=\alpha+\beta \times \text { Primary }_{s t}+\boldsymbol{\gamma} \mathbf{A}_{a s t}+\boldsymbol{\delta} \mathbf{Z}_{s t}+\boldsymbol{\sigma}_{s}+\boldsymbol{\tau}_{t}
$$

where $p_{\text {ast }}$ is the probability that a fatality was wearing a seat belt and the model coefficients are defined similarly as for the Poisson regression but on the log odds scale. The grouped logistic regression is fit using maximum likelihood [27], and standard errors were clustered at the state level [28,29]. We used coefficients from these models to generate, respectively, marginal predicted motor vehicle crash death rates (Poisson model) and proportions of fatalities wearing seat belts (grouped logit model). Marginal predictions were restricted to the observed data (i.e., we did not average predictions over the prior data). We calculated differences and rate ratios of our marginal predictions and used the delta method to calculate standard errors for these quantities. We also checked for compatibility between the prior and the data using the approach outlined by Greenland [30], akin to a test of homogeneity, in which a low $p$-value may indicate incompatibility between the prior and the observed data. 


\section{Construction of the prior data}

Improvements in computing power and the incorporation of Bayesian analytic techniques in commercial and open source software have improved the prospects for utilizing Bayesian analysis in policy research [31], usually via repeated sampling such as Markov chain Monte Carlo. However, Bayesian analysis may also be implemented via data augmentation [30], which adds observations representing the prior information to the empirical dataset. The data augmentation approach imposes a prior distribution on our coefficient of interest $(\beta)$ of the generalized-conjugate form that allows considerable flexibility to incorporate diverse priors [32]. We adopted a data augmentation approach for two reasons. One is the ease with which data augmentation simplifies the analysis, since it may be implemented using traditional likelihood-based algorithms [33]. The second reason is that analysis of state-level policy changes typically need to incorporate cluster robust inference [29] and, to our knowledge, developing priors (or hyperpriors) to account for alternative correlation structures (e.g. serial correlation) in state-level panel data is still an area of active research [34].

Bayesian analysis via data augmentation proceeds similarly to traditional likelihood-based regression, but the information encoded in the priors is added to the dataset as additional observations. Since our only interest is in the parameter on primary enforcement, we only added a single additional observation for each prior, making our analysis semi-Bayesian rather than fully Bayesian (see eAppendix for a comparison with fully Bayesian models). In essence, constructing the prior data translates the prior into the number of events (crash deaths or belted deaths) that would have come from a prior experiment on the question at hand. That is, we ask, what previous experiment would convey the same information as our priors? For Poisson models $A$ equals the observed count of deaths for observed records, and $A=S^{2} / v$ gives the number of additional deaths represented by the prior data record, where $S$ is a rescaling factor to improve asymptotic approximation [35] and $v$ is the prior variance. The offset term is $\log$ (vehicle miles traveled) for observed records and calculated as $A / e^{m / S}$, where $m$ is the prior mean. For the prior observations the exposure of interest (primary law) is set to $1 / S$ and all other covariates are set to 0 . Table 1 provides an overview of the parameters resulting from our selection of priors.

We analyzed the augmented data using maximum-likelihood Poisson regression with cluster-robust variance (clustered at the state level [29]). The maximum likelihood estimate of the mean of $\beta$ gives the approximate posterior median and the $95 \%$ confidence limits for $\beta$ are the approximate posterior limits (2.5th and 97.5th posterior percentiles) [33].

\section{Sensitivity analysis}

Because Poisson regression assumes the mean and variance are constant, we also ran a negative binomial model to account for overdispersion, though we note that unconditional negative binomial fixed effects models may be subject to the "incidental parameters" problem and conditional negative binomial models are not true fixed effects models $[36,37]$. In additional models, we tested for lagged policy effects by allowing the impact of the law to occur 1 year after implementation. We also investigated different control groups and conducted analyses restricting the control group to states that either maintained exclusively secondary or exclusively primary enforcement throughout the entire period of analysis. Additionally, given the decrease in national motor vehicle crash death rates after the Great Recession [38], which began in December 2007, we estimated models that only used the pre-recession time period from 2000-2007. For each of these models we used subjective priors since they represent the strongest prior information about the policy impact. We also considered whether the fraction of fatal crashes occurring on rural roads or involving alcohol may be time-varying confounders and ran additional models that: a) included these two covariates measured in the same state-year of the crash; b) excluded both covariates; and c:) included 1-year lagged values of both covariates to avoid conditioning on factors potentially affected by the treatment. 


\section{Results}

Table 2 shows means and standard deviations for covariates among states that maintained secondary enforcement, already had primary enforcement, and upgraded from secondary to primary enforcement. Notable differences in, for example, exposure to speed limit and blood alcohol policies, between the kinds of states that did and did not alter their seat belt policy suggests that unmeasured fixed state characteristics could confound the effect of upgrading to primary enforcement. Our difference-in-differences analysis should help to mitigate this source of bias.

Table 3 displays our semi-Bayesian estimates of the impact of upgrading (eFigure 4 shows the prior, likelihood, and posterior distributions on the rate difference and rate ratio scale). The non-informative prior generates posterior estimates similar to a frequentist analysis, which show little evidence for any effect on fatality rates. Upgrading to primary enforcement reduced fatality rates by 0.24 deaths per billion vehicle miles traveled $(95 \%$ posterior limits $-0.72,0.24)$. Using our empirical prior, which was centered on a $5 \%$ reduction in crash fatality rates, pulls the posterior estimate slightly further from the null (Rate Difference [RD] $-0.32,95 \%$ posterior limits $-0.82,0.17$ ), but because the likelihood estimate provides more information, it tends to dominate the posterior and still suggests limited evidence of an impact on crash deaths. Using our subjective prior provides qualitatively similar results (RD - $0.37,95 \%$ posterior limits $-0.90,0.16, \mathrm{RR}$ of $0.96,95 \%$ posterior interval $0.91,1.02)$, and $p$-values for tests of compatibility between the data and prior were 0.99 for non-informative, 0.72 for empirical, and 0.18 for subjective priors.

Table 4 shows the posterior estimates from the grouped logistic regression for the proportion of deaths wearing seat belts (eFigure 5 shows the prior, likelihood, and posterior distributions on the risk difference and risk ratio scale). In contrast to the results for fatality rates, the posterior estimates using a non-informative prior do suggest that upgrading to primary enforcement increases the proportion of deaths wearing seat belts by around 6 percentage points $(95 \%$ posterior limits 5,7$)$. The posterior estimates using both empirical and subjective priors are nearly identical (posterior limits of 5 and 8 percentage points for both estimates), and $p$-values for tests of compatibility between the data and prior were 0.99 for non-informative, 0.26 for empirical, and 0.07 for subjective priors.

Sensitivity analyses (eTables 2 and 3) generally supported the main results, showing limited evidence of impact on crash death rates, and similar positive estimates for the impact on the proportion of decedents wearing seat belts. The fully Bayesian analysis also produced estimates similar to our semi-Bayesian results (eTable 4), and our estimates were not sensitive to the inclusion of alcohol-involved or rural road deaths (eTable 5). Complete regression results for the fully-adjusted frequentist difference-in-difference models are given in eTables 6 and 7 ).

\section{Discussion}

In this study we provide a semi-Bayesian analysis of the impact on fatalities of upgrading seat belt laws to primary enforcement that explicitly accounts for prior evidence through the use of data augmentation. We encoded information from prior studies on primary enforcement upgrades using empirical priors from random-effects meta-analysis, as well as subjective priors based on policy documents. For the outcome of fatality rates, the posterior distribution suggests a weak impact of upgrading, on the order of a $3 \%$ decrease or 0.3 fewer deaths per billion vehicle miles traveled, even with priors centered at a $10 \%$ reduction. To achieve posterior estimates more consistent with current claims [1,8,9] about the expected mortality benefits of upgrading to primary enforcement on crash fatality rates would require considerably stronger, and perhaps unrealistic, priors. With respect to the impact on the proportion of deaths wearing seat belts, our posterior estimates using either empirical or subjective priors are a relatively precisely estimated 6 percentage point increase. This is consistent with a beneficial impact of upgrading, but the magnitude of this estimate is notably smaller than the 12 to 18 percentage point increase cited in some policy documents [16].

Overall, our analysis suggests that current policy documents $[1,3,8,9]$ could be updated to reflect the totality of evidence on primary enforcement of seat belt laws. For the 15 states with secondary enforcement 
that may be considering upgrading to primary, the potential benefits of increasing seat belt use on reducing mortality should be considered in light of other potential policy impacts. In this paper we are chiefly concerned with providing an estimate of the impact of upgrading to primary enforcement on occupant fatalities and seat belt use, rather than an all-things-considered judgement. Concerns that primary enforcement laws may lead to increases in police harassment of minority drivers are longstanding, but there is little rigorous empirical evidence on this question [39]. Clearly, concerns about paternalism, police harassment [40], and the additional costs of enforcement (such as "Click-It-Or-Ticket" or other media campaigns) are relevant to any policy decision, but a full accounting of those impacts is beyond the scope of this paper.

We do find evidence that upgrading to primary enforcement led to increases of roughly 6 to 7 percentage points in the proportion of crash deaths wearing a seatbelt. Although this effect is smaller than the estimates usually given in policy documents regarding the benefits of primary enforcement, it nevertheless does provide additional evidence that primary enforcement increases seat belt use. More intriguing is the the combined evidence that, despite the increase in seat belt use, we do not estimate important decreases in crash death rates. This suggests that further increases in seat belt use may not provide the same degree of benefit today as was seen in the past. There are several potential reasons why this may be true, one of which is effect measure modification. It is relatively well established in the traffic safety literature that early adopters of seat belts tended to be less risky drivers [41,42]. That is to say, when the first mandatory seat belt laws were implemented in the 1980s and seat belt use was infrequent, those who complied with mandatory laws tended to be drivers that were less likely to be involved in more severe crashes [43]. Now that seat belt use is much more common, the mortality benefits of recent upgrades to primary enforcement may be diluted because those recently converting to seat belt use are are no longer among the population of safer-than-average drivers, although there is little direct evidence to that effect.

Another potential explanation for the reduced impact on crash deaths relative to prior literature is that the traffic safety environment has changed in several ways since the 1990s when many initial studies of primary enforcement were first conducted. US seat belt use is now approaching 90\% [44] and other environmental factors such as changes in road design and additional vehicle safety features (front and side air bags, electronic stability control, daytime running lights, lane control, etc.) may now be playing a more prominent role. Recent studies of changes in vehicle design suggest strong impacts on motor vehicle crash death rates $[5,6]$, so it is not clear whether states presently considering upgrading their existing seat belt laws to primary enforcement can expect the benefits seen in prior studies.

Our analysis has limitations. The difference-in-differences model we used assumes that pre-intervention trends between states that did and did not change policy are parallel, and, of course, that there are no unmeasured factors that are associated with the timing of policy adoption and also affect outcomes. Our current estimates, as well as prior frequentist results [45], were robust to alternative control groups, lagging the policy change by one year, and restriction to years prior to the Great Recession, but unmeasured confounding can never be ruled out. We did not conduct a systematic review to inform our empirical priors and we used our subjective assessments of prior study quality to arrive at the meta-analyzed sample. It is possible that we may have missed other relevant studies, but given the extent to which the likelihood dominates our inference, it seems unlikely that any missed studies would lead to substantively different conclusions about the magnitude or sign of the effect [46]. Our results reflect the subjectivity of our chosen priors, and we have made our computing code and data publicly available (https://osf.io/em2y7/) to allow others to examine the influence of using different credible priors [31].

\section{Acknowledgments}

We thank two anonymous reviewers, Rich MacLehose, Alexandra M. Schmidt, and participants at the Population Association of America Annual Meeting for feedback on an earlier version of this manuscript. 


\section{References}

[1] Sauber-Schatz EK, Ederer DJ, Dellinger AM, Baldwin GT. Vital Signs: Motor Vehicle Injury Prevention - United States and 19 Comparison Countries. MMWR Morb Mortal Wkly Rep. 2016;65(26):672-7.

[2] Ringel JS, Zmud J, Connor K, Powell D, Chow BG, Ecola L, et al. Costs and Effectiveness of Interventions to Reduce Motor Vehicle-Related Injuries and Deaths. RAND Corporation; 2015. Available from:

http://www.rand.org/content/dam/rand/pubs/tools/TL100/TL144z1/RAND_TL144z1.pdf.

[3] Centers for Disease Control and Prevention (CDC). Motor Vehicle Prioritizing Interventions and Cost Calculator for States (MV PICCS);. Available from:

https://www.cdc.gov/motorvehiclesafety/calculator/index.html.

[4] National Highway Traffic Safety Administration. Primary Enforcement Saves Lives: The Case for Upgrading Secondary Safety Belt Laws. Report No DOT HS. 2006;810:649.

[5] Farmer CM, Lund AK. Trends over time in the risk of driver death: what if vehicle designs had not improved? Traffic Inj Prev. 2006 Dec;7(4):335-42.

[6] Farmer CM, Lund AK. The Effects of Vehicle Redesign on the Risk of Driver Death. Traffic Inj Prev. $2015 ; 16(7): 684-90$.

[7] Nichols JL, Ledingham KA. The impact of legislation, enforcement, and sanctions on safety belt use. vol. 601. Transportation Research Board; 2008.

[8] Ecola L, Batorsky B, Ringel JS. Using Cost-Effectiveness Analysis to Prioritize Spending on Traffic Safety. Rand Corporation; 2015.

[9] Goodwin A, Thomas L, Kirley B, Hall W, O'Brien N, Hill K. Countermeasures that work: A highway safety countermeasure guide for State highway safety offices, Eighth edition. National Highway Traffic Safety Administration; 2015.

[10] Shadish WR, Cook TD, Campbell DT. Experimental and quasi-experimental designs for generalized causal inference. Boston: Houghton Mifflin; 2001.

[11] Meyer BD. Natural and Quasi-Experiments in Economics. J Bus Econ Stat. 1995;13(2):151-161.

[12] Angrist JD, Pischke JS. Mostly harmless econometrics: an empiricist's companion. Princeton Univ Press; 2008.

[13] Cohen A, Einav L. The effects of mandatory seat belt laws on driving behavior and traffic fatalities. Rev Econ Stat. 2003;85(4):828-843.

[14] Farmer CM, Williams AF. Effect on fatality risk of changing from secondary to primary seat belt enforcement. J Safety Res. 2005;36(2):189-94.

[15] Houston DJ, Richardson Jr LE. Reducing traffic fatalities in the American States by upgrading seat belt use laws to primary enforcement. J Policy Anal Manag. 2006;25(3):645-659.

[16] Hedlund J, Gilbert SH, Ledingham KA, Preusser DF. How States Achieve High Seat Belt Use Rates. National Highway Traffic Safety Administration; 2008. DOT HS 810962.

[17] Borenstein M, Hedges LV, Higgins JPT, Rothstein HR. Introduction to meta-analysis. Chichester, U.K.: John Wiley \& Sons; 2009.

[18] Higgins JPT, Thompson SG. Quantifying heterogeneity in a meta-analysis. Stat Med. 2002 Jun;21(11):1539-58. 
[19] Riley RD, Higgins JPT, Deeks JJ. Interpretation of random effects meta-analyses. BMJ. 2011 Feb;342:d549.

[20] National Bureau of Economic Research. NHTSA's Fatality Analysis Reporting System (FARS) Data 1975-2011; Dec 1, 2015. Available from: http://www.nber.org/data/fars.html [cited 6 Apr 2016].

[21] Insurance Institute for Highway Safety. Safety belts; September, 2015. Available from: http://www.iihs.org/iihs/topics/laws/safetybeltuse [cited 17 Sep 2015].

[22] National Highway Traffic Safety Adminstration. Fatality Analysis Reporting System (FARS) Encyclopedia: Fatalities and Fatality Rates by State; 2015. Available from: http://www-fars.nhtsa.dot.gov/States/StatesFatalitiesFatalityRates.aspx [cited 17 Sep 2015].

[23] Insurance Institute for Highway Safety. Highway Safety Topics;. Available from: http://www.iihs.org/iihs/topics\#statelaws [cited 17 Sep 2016].

[24] United States Department of Justice, Federal Bureau of Investigation. Uniform Crime Reporting Program Data: Police Employee (LEOKA) Data, 2000-2014.;. Available from: http://www.icpsr.umich.edu/icpsrweb/NACJD/series/00057.

[25] Haughwout SP, LaVallee RA, Castle IJP. Apparent per capita alcohol consumption: National, state and regional trends, 1977-2014. National Institute on Alcohol Abuse and Alcoholism; 2016. Available from: http://pubs.niaaa.nih.gov/publications/surveillance104/CONS14.pdf.

[26] US Bureau of the Census. State Median Income; September 16, 2015. Available from: https://www. census.gov/hhes/www/income/data/statemedian/ [cited 17 Sep 2015].

[27] StataCorp. Stata 13 Base Reference Manual. College Station, TX: Stata Press; 2013.

[28] Bertrand M, Duflo E, Mullainathan S. How Much Should We Trust Differences-in-Differences Estimates? Q J Econ. 2004;119(1):249-275.

[29] Cameron AC, Miller DL. A practitioner's guide to cluster-robust inference. J Hum Resour. $2015 ; 50(2): 317-372$.

[30] Greenland S. Bayesian perspectives for epidemiological research: I. Foundations and basic methods. Int J Epidemiol. 2006 Jun;35(3):765-75.

[31] Fienberg SE. Bayesian Models and Methods in Public Policy and Government Settings. Stat Sci. 2011 may;26(2):212-226. Available from: http://dx.doi.org/10.1214/10-sts331.

[32] Greenland S. Generalized conjugate priors for Bayesian analysis of risk and survival regressions. Biometrics. 2003 Mar;59(1):92-9.

[33] Greenland S. Bayesian perspectives for epidemiological research. II. Regression analysis. Int J Epidemiol. 2007 Feb;36(1):195-202.

[34] Szpiro AA, Rice KM, Lumley T. Model-robust regression and a Bayesian "sandwich" estimator. Ann Appl Stat. 2010 dec;4(4):2099-2113. Available from: http://dx.doi.org/10.1214/10-aoas362.

[35] Sullivan S, Greenland S. Bayesian regression in SAS software. Int J Epidemiol. 2013 Feb;42:308-17.

[36] Allison PD, Waterman RP. Fixed-effects negative binomial regression models. Sociological methodology. 2002;32(1):247-265.

[37] Hilbe JM. Negative binomial regression. 2nd ed. Cambridge, UK: Cambridge University Press; 2011.

[38] He MM. Driving through the Great Recession: Why does motor vehicle fatality decrease when the economy slows down? Soc Sci Med. 2016 Apr;155:1-11. 
[39] Eby DW, Kostyniuk LP, Molnar LJ, Vivoda JM, Miller LL. The effect of changing from secondary to primary safety belt enforcement on police harassment. Accid Anal Prev. 2004 Sep;36(5):819-28.

[40] Harris DA. The Stories, the Statistics, and the Law: Why "Driving while Black" Matters. Minn Law Rev. 1999;84:265.

[41] Evans L. Human behavior feedback and traffic safety. Human factors. 1985;27(5):555-576.

[42] Hemenway D. Nervous Nellies and dangerous Dans. Journal of Policy Analysis and Management. 1993;12(2):359-363.

[43] Dee TS. Reconsidering the effects of seat belt laws and their enforcement status. Accid Anal Prev. 1998 Jan;30(1):1-10.

[44] Chen YY. Seat Belt Use in 2014-Use Rates in the States and Territories. Washington, DC: National Highway Traffic Safety Administration; 2015. DOT HS 812149.

[45] Harper S, Strumpf EC. Primary Enforcement of Mandatory Seat Belt Laws and Motor Vehicle Crash Deaths. Am J Prev Med. 2017 Mar;.

[46] Gelman A, Carlin J. Beyond power calculations assessing type S (sign) and type M (magnitude) errors. Perspectives on Psychological Science. 2014;9(6):641-651. 
Table 1: Prior record construction for (a) Poisson regression models and (b) grouped logistic regression models

(a) Poisson model: Fatalities per vehicle mile traveled (VMT)

\begin{tabular}{lccccc}
\cline { 2 - 5 } Prior & $R R$ & $\operatorname{Var}(\ln [R R])$ & $95 \%$ limits & Deaths & Implied VMT (billions) \\
\hline Non-informative & 1.0 & 100.0 & $3 \mathrm{e}-9,4 \mathrm{e}+8$ & 6.25 & 6.51 \\
Empirical & 0.95 & 0.005 & $0.83,1.09$ & 125000 & 129841 \\
Subjective & 0.90 & 0.003 & $0.80,1.00$ & 208333 & 215970
\end{tabular}

(b) Grouped logit model: Proportion of deaths wearing seat belts

\begin{tabular}{lccccc}
\cline { 2 - 5 } Prior & $R R$ & $\operatorname{Var}(\ln [R R])$ & $95 \%$ limits & Deaths & Implied offset \\
\hline Non-informative & 1.0 & 100.0 & $3 \mathrm{e}-9,4 \mathrm{e}+8$ & 4 & 0 \\
Empirical & 1.30 & 0.009 & $1.08,1.58$ & 22222 & -0.0693 \\
Subjective & 1.36 & 0.007 & $1.15,1.60$ & 28571 & -0.1099 \\
\hline
\end{tabular}

Note: Both models use a scaling factor of $s=25$. RR $=$ Rate Ratio 
Table 2: Covariates for states by enforcement of mandatory seat belt laws, 2000-2016.

\begin{tabular}{|c|c|c|c|c|c|c|}
\hline \multirow[b]{2}{*}{ Variable } & \multicolumn{2}{|c|}{$\begin{array}{l}\text { Remained } \\
\text { Secondary }\end{array}$} & \multicolumn{2}{|c|}{ Remained Primary } & \multicolumn{2}{|c|}{$\begin{array}{l}\text { Upgrade to } \\
\text { Primary }\end{array}$} \\
\hline & Mean & SD & Mean & SD & Mean & SD \\
\hline \multicolumn{7}{|l|}{ Age group, \% } \\
\hline $0-10$ years & 13 & 33 & 14 & 34 & 13 & 33 \\
\hline $10-14$ years & 7 & 25 & 7 & 26 & 7 & 25 \\
\hline $15-19$ years & 7 & 26 & 7 & 26 & 7 & 25 \\
\hline 20-24 years & 7 & 25 & 7 & 26 & 7 & 25 \\
\hline $25-34$ years & 13 & 34 & 14 & 35 & 13 & 34 \\
\hline $35-44$ years & 14 & 34 & 14 & 35 & 14 & 34 \\
\hline $45-54$ years & 14 & 35 & 14 & 35 & 14 & 35 \\
\hline $55-64$ years & 12 & 32 & 11 & 31 & 11 & 32 \\
\hline $65-74$ years & 7 & 26 & 7 & 25 & 8 & 26 \\
\hline $75+$ years & 6 & 25 & 6 & 23 & 7 & 25 \\
\hline \multicolumn{7}{|l|}{ Max speed limit, \% } \\
\hline$<70 \mathrm{MPH}$ & 60 & 49 & 30 & 46 & 36 & 48 \\
\hline $70 \mathrm{MPH}$ & 9 & 29 & 48 & 50 & 57 & 49 \\
\hline$>70 \mathrm{MPH}$ & 30 & 46 & 22 & 41 & 7 & 26 \\
\hline \multicolumn{7}{|l|}{ BAC law, $\%$} \\
\hline $\mathrm{BAC}<0.10$ & 13 & 32 & 5 & 20 & 18 & 37 \\
\hline $\mathrm{BAC}<0.08$ & 85 & 34 & 95 & 20 & 87 & 31 \\
\hline \multicolumn{7}{|l|}{ Graduated license, \% } \\
\hline Night restriction & 90 & 29 & 95 & 20 & 90 & 29 \\
\hline Passenger restriction & 63 & 48 & 85 & 35 & 57 & 49 \\
\hline Alcohol per capita, gallons & 3 & 0 & 2 & 0 & 3 & 0 \\
\hline Police per capita & 16 & 6 & 16 & 6 & 17 & 4 \\
\hline Median income $(10,000 s)$ & 6 & 1 & 6 & 1 & 6 & 1 \\
\hline VMT (billions) & 73 & 32 & 175 & 112 & 89 & 57 \\
\hline Unbelted deaths, $\%$ & 58 & 16 & 45 & 17 & 52 & 18 \\
\hline
\end{tabular}

$\mathrm{SD}=$ standard deviation; $\mathrm{MPH}=$ miles per hour; $\mathrm{BAC}=$ blood alcohol concentration; $\mathrm{VMT}=$ vehicle miles traveled. 
Table 3: Estimated effect of upgrading from secondary to primary enforcement of seat belt laws on motor vehicle crash death rates per billion VMT, US states, 2000-2016.

\begin{tabular}{|c|c|c|c|c|c|c|}
\hline & \multicolumn{2}{|c|}{$\begin{array}{l}\text { Non-informative prior: } \\
\qquad N(\ln (1), 100)\end{array}$} & \multicolumn{2}{|c|}{$\begin{array}{c}\text { Empirical prior: } \\
N(\ln (0.95), 0.005)\end{array}$} & \multicolumn{2}{|c|}{$\begin{array}{l}\text { Subjective prior: } \\
N(\ln (0.90), 0.003)\end{array}$} \\
\hline & Secondary & Primary & Secondary & Primary & Secondary & Primary \\
\hline Estimated Rates & $\begin{array}{c}9.7 \\
{[9.5,10.0]}\end{array}$ & $\begin{array}{c}9.5 \\
{[9.3,9.7]}\end{array}$ & $\begin{array}{c}9.8 \\
{[9.5,10.0]}\end{array}$ & $\begin{array}{c}9.5 \\
{[9.2,9.7]}\end{array}$ & $\begin{array}{c}9.8 \\
{[9.5,10.1]}\end{array}$ & $\begin{array}{c}9.4 \\
{[9.2,9.7]}\end{array}$ \\
\hline \multicolumn{7}{|l|}{ Effect measures } \\
\hline Rate difference & & $\begin{array}{c}-0.24 \\
{[-0.72,0.24]}\end{array}$ & & $\begin{array}{c}-0.32 \\
{[-0.82,0.17]}\end{array}$ & & $\begin{array}{c}-0.37 \\
{[-0.90,0.16]}\end{array}$ \\
\hline Rate ratio & & $\begin{array}{c}0.98 \\
{[0.93,1.02]}\end{array}$ & & $\begin{array}{c}0.97 \\
{[0.92,1.02]}\end{array}$ & & $\begin{array}{c}0.96 \\
{[0.91,1.02]}\end{array}$ \\
\hline
\end{tabular}

Note: Poisson regression with vehicle miles traveled (billions) as offset. Standard errors clustered by state. $95 \%$ posterior limits in brackets. Adjusted for age group, presence or absence of speed limit laws $(\leq 65,70,>70)$, graduated driver's license laws (night restrictions, passenger restrictions), maximum blood alcohol content laws $(0.08,0.10 \mathrm{~g} / \mathrm{dl})$, alcohol consumption per capita, police officers per capita, state median income, and state and year fixed effects. $(n=8501)$. 
Table 4: Estimated effect of upgrading from secondary to primary enforcement of seat belt laws on the proportion of crash deaths wearing seat belts, US states, 2000-2016.

\begin{tabular}{|c|c|c|c|c|c|c|}
\hline & \multicolumn{2}{|c|}{$\begin{array}{c}\text { Non-informative prior: } \\
N(\ln (1), 100)\end{array}$} & \multicolumn{2}{|c|}{$\begin{array}{c}\text { Empirical prior: } \\
N(\ln (1.30), 0.009)\end{array}$} & \multicolumn{2}{|c|}{$\begin{array}{l}\text { Subjective prior: } \\
N(\ln (1.36), 0.007)\end{array}$} \\
\hline & Secondary & Primary & Secondary & Primary & Secondary & Primary \\
\hline Estimated Risk & $\begin{array}{c}0.36 \\
{[0.35,0.37]}\end{array}$ & $\begin{array}{c}0.42 \\
{[0.42,0.43]}\end{array}$ & $\begin{array}{c}0.36 \\
{[0.35,0.37]}\end{array}$ & $\begin{array}{c}0.42 \\
{[0.42,0.43]}\end{array}$ & $\begin{array}{c}0.36 \\
{[0.35,0.37]}\end{array}$ & $\begin{array}{c}0.43 \\
{[0.42,0.43]}\end{array}$ \\
\hline Effect measure & & & & & & \\
\hline Risk difference & & $\begin{array}{c}0.06 \\
{[0.05,0.07]}\end{array}$ & & $\begin{array}{c}0.06 \\
{[0.05,0.08]}\end{array}$ & & $\begin{array}{c}0.07 \\
{[0.05,0.08]}\end{array}$ \\
\hline Risk ratio & & $\begin{array}{c}1.17 \\
{[1.13,1.21]}\end{array}$ & & $\begin{array}{c}1.17 \\
{[1.13,1.22]}\end{array}$ & & $\begin{array}{c}1.18 \\
{[1.13,1.24}\end{array}$ \\
\hline
\end{tabular}

Note: Grouped logistic regression. Standard errors clustered by state. $95 \%$ posterior limits in brackets. Adjusted for age group, presence or absence of speed limit laws $(\leq 65,70,>70)$, graduated driver's license laws (night restrictions, passenger restrictions), maximum blood alcohol content laws $(0.08,0.10 \mathrm{~g} / \mathrm{dl})$, alcohol consumption per capita, police officers per capita, state median income, and state and year fixed effects $(n=8501)$. 
eAppendix: Would Stronger Seat Belt Laws Reduce Motor Vehicle Crash Deaths? A Semi-Bayesian Analysis

Sam Harper

2019-03-21

1 Current state policies

eFigure 1: Current mandatory seat belt laws for adults as of 2018

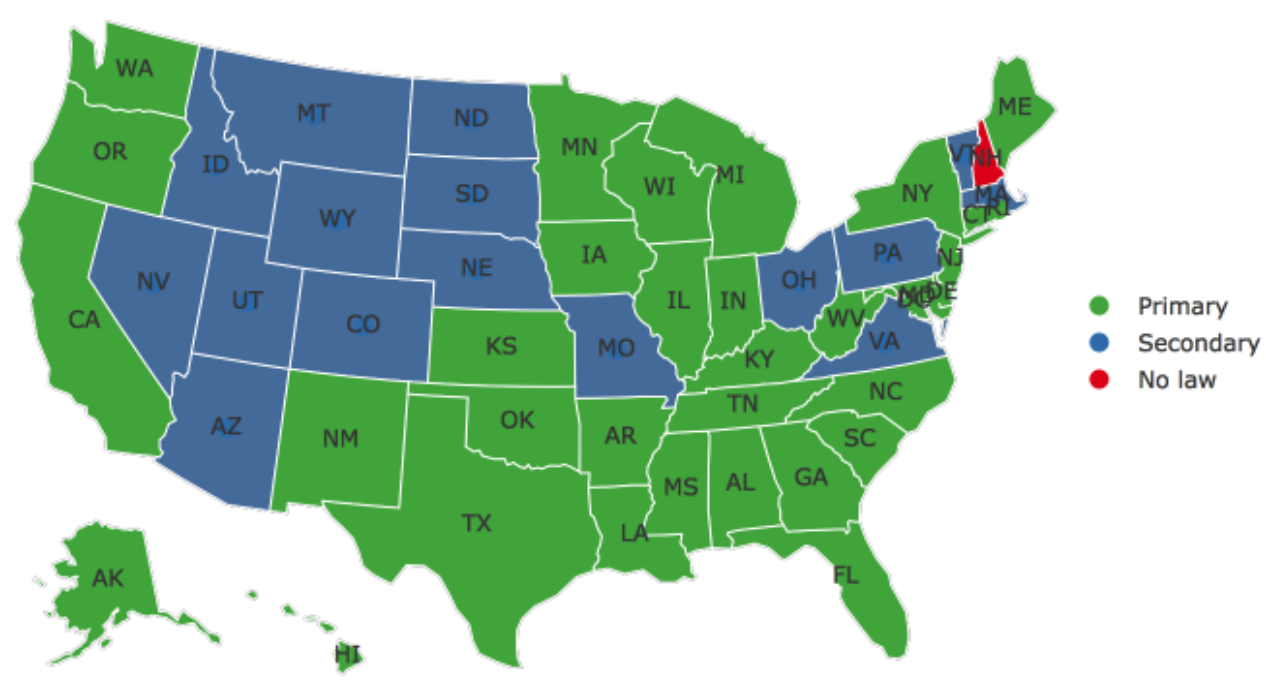




\section{Prior literature}

To incorporate prior information on the impact of seat belt law upgrades on fatalities, we reviewed prior studies, paying particular attention to those cited as evidence for upgrading to primary enforcement [1-5]. Early studies compared the impact of moving from no law to a law with either primary or secondary enforcement, and found benefits for any legislation, but stronger benefits for primary laws [6-9]. However, because all states except New Hampshire presently have a secondary law, our prior should reflect the potential impact of upgrading from secondary to primary enforcement.

A key challenge in estimating the impact of primary enforcement upgrades is the non-random process of policy adoption. States that upgrade their policy from secondary to primary enforcement are likely to be different from those that don't upgrade in ways that are correlated with MVC rates, leading to biased estimates of policy impact. As an example, California was the first state to upgrade to primary enforcement in 1993. Thus, simply comparing fatality rates in states with primary vs. secondary enforcement laws is

likely to overestimate any benefit. For example, a recent study by Lee and colleagues [10] found that states with primary enforcement has fatal crash rates that were $17 \%$ lower than secondary states, an estimate considerably higher than those we describe below. We therefore did not include this estimate because key sources of confounding, namely unmeasured state characteristics and time trends, were not controlled for in the study, though perhaps it could be considered as an upper bound for our prior.

\subsection{Effect on MVC fatality rates}

Two systematic reviews of mandatory seat belt laws were reported in the early 2000s by the Guide to Community Preventive Servies Task Force [11,12]. Dinh-Zarr et al. [11] cited 5 studies as providing evidence on the "incremental effectiveness" of primary vs. secondary laws. However, 4 of these studies [6-9] used time series data prior to the first state upgrading from secondary to primary in 1993 and the other [13] captures the change in California, but with only a single year of post-law data. Shults et al. [12] report between $8 \%$ and 15\% decreases in fatal and non-fatal injuries combined, citing Jonah and Grant [14] and Farmer and Williams [15]. Only the Farmer and Williams study estimated the impact of upgrading from secondary to primary enforcement.

More recently, Nichols et al. [2] reported a median of 7-8\% decline based on upgrades (no standard error was reported). Salzberg and Moffat [16] reported a $13.4 \%$ decrease (no uncertainty estimate) in occupant fatalities after an upgrade to primary enforcement in Washington state. Voas et al. [17] also report "median $15 \%$ reduction in alcohol-related deaths and a median 5\% reduction in non-alcohol-related deaths in five case study states that implemented primary law upgrades." Given that National Highway Traffic Safety Administration reports that approximately $30 \%$ of fatalities can be considered alcohol-related, this would suggest an overall impact of around $8 \%$, consistent with prior estimates.

We used 3 studies to inform our empirical priors, all of which used an interrupted time series with an unaffected control group [18] or a difference-in-differences [19,20] design. These studies all use within-state variation in mandatory laws (i.e., "switching" from a law with secondary to primary enforcement) and control for secular trends, either using fixed effects for time or ARIMA models, and at the very least are protected from bias due to fixed state characteristics or common time-varying factors.

- Cohen and Einav [21] used a difference-in-differences design to estimate the impact of mandatory laws on MVA fatality rates using 1983-1997 FARS data on all 50 states and DC (additionally, they instrumented for seat belt use to assess its impact as well). In addition to state and year fixed effects they also control for a large number of time-varying covariates (demographics, median income, unemployment, crime rates, speed limit laws, traffic density, drunk driving laws). They report (Table 4) that switching to primary enforcement increases seat belt use by 13.4 percentage points (no standard error but $p<0.01$ ) and the reduced form estimate of the effect on occupant fatality rates (Table 5) is $-0.0002(\mathrm{SE}=0.0004)$ fatalities per VMT and $-0.030(\mathrm{SE}=0.024)$ per $\log ($ fatalities per $\mathrm{VMT}$ ). We converted their estimate per VMT (which is technically per million VMT since their 
estimates of VMT are in millions as reported by "Highway Statistics") to 0.2 deaths per billion VMT. Their estimates of $\log$ VMT can be converted to estimated $R R s$ by taking the $95 \%$ confidence limits for the $\log R R$ implied by the standard error and exponentiating, which gives $R R=0.97$ and $95 \% C I=0.93,1.02$.

- Farmer and Williams [15] used 1989-2003 FARS data for 10 states that upgraded and 14 that did not and employed a time-series cross sectional regression model (adjusted for the unemployment rate) to estimate the effect of upgrading to primary enforcement on fatality rates per billion VMT. Because they estimated proportional reduction in driver fatality rates as $E=1-\exp (\beta)$ this suggests they used a log-linear model. They report (Table 3) a model estimate of $-0.07248(\mathrm{SE}=0.0217)$, implying a $7 \%$ reduction in driver fatality rates per billion VMT. Using the point estimate and implied confidence limits for their effect, we calculated a $R R=0.93$ and $95 \% C I=0.89,0.97$. To provide an estimate of the absolute reduction, we took the observed fatality rate in the treated states and the end of follow-up (6.36 per billion VMT) and estimated the counterfactual rate implied by the law effect: $6.36 * 1.07248=6.82$ and subtracted the difference, which provided an estimate of $6.36-6.82=-0.497$ per billion VMT. Repeating this exercise with the $95 \%$ limits of the effect provided a $95 \%$ CI of -0.827 to -0.196 .

- Houston and Richardson [22] used a similar design as Cohen and Einav [21] with 1990-2002 FARS data for all 50 states and DC. They also include in their fixed effects model controls for age distribution, income per capita, population density, alcohol consumption, speed limit, drunk driving, and graduated driver's license laws. They report (Table 4) an effect estimate of -6.647 occupant deaths per 10 billion VMT in states that upgrade to primary (vs. remaining secondary), with a SE of 2.014 , which we converted to $95 \%$ confidence limits of -10.59 and -2.70 . Houston and Richardson report (Table 3) similar estimates for driver deaths per 10 billion VMT (estimate $=-5.126, \mathrm{SE}=$ 1.549). They also report that the relative impact of upgrading on occupant fatalities (p.655) is a $4.7 \%$ decrease (implying a $R R=0.953$ ), which suggests a base rate of $6.647 / .047=141.43$ deaths per 10 billion VMT. We used this implied base rate and the $95 \%$ confidence limits of the absolute effect to estimate the $95 \%$ limits of the $R R$, which we calculated as $(141.43-10.59) / 141.43=0.93$ and $(141.43-2.70) / 141.43=0.98$.

We took these 3 sets of estimates and conducted a random effects meta-analysis [23], which treats each study as a separate estimate and combines them into a summary measure, assuming that the studies are sampled from a distribution of possible studies. We tested for heterogeneity across studies using Cochran's $Q$ statistic [24]. Below (eFigure2) we show forest plots for both the impact on MVC fatality rates and on the proportion of fatalities belted. The summary estimate for MVC fatality rates is 4.75 fewer deaths per 10 billion VMT, with a $95 \%$ confidence interval of $(-6.78$ to -2.72$)$, and there is not enough evidence to reject the assumption of homogeneity in the effects $Q=1.78,(d f=2), p=0.411$. On the rate ratio scale the summary estimate is $0.95(0.93,0.97)$, again with little evidence against homogeneity across studies. 
eFigure 2: Random effects meta-analysis (with 95\% prediction interval) of prior studies of upgrades to primary enforcement on fatalities per billion VMT

(a) Rate Difference (RD) per billion VMT

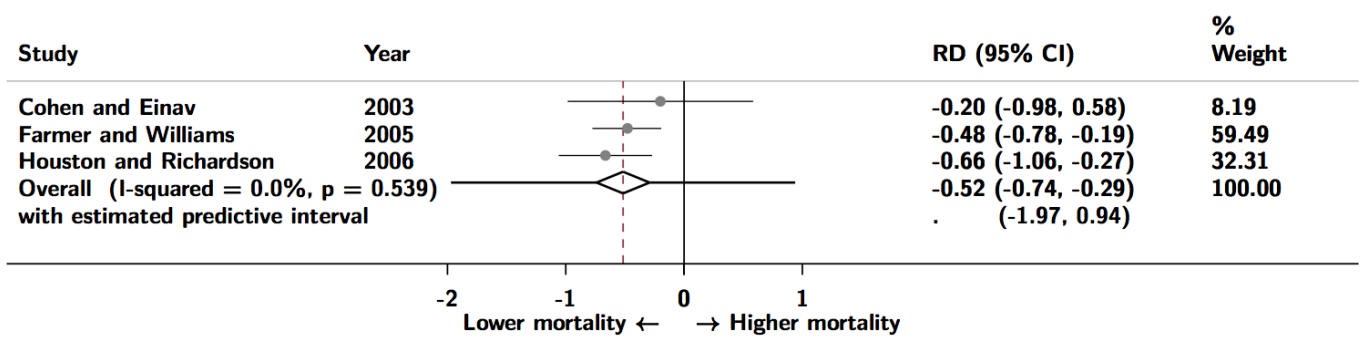

(b) Rate Ratio (RR)

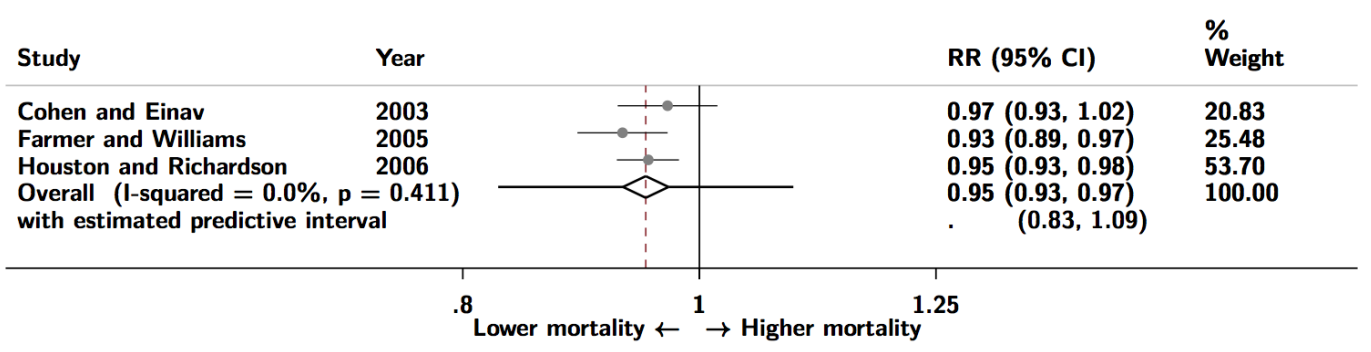

\subsection{Effect on the proportion of fatalities wearing seat belts}

With respect to the proportion of occupant fatalities wearing seat belts, the report by Nichols et al. [2] provides estimates for the proportion of individuals killed wearing seat belts. Among occupants killed (using FARS data) they report (in their Table 2 on p.10) an average of a 7 percentage point increase in belt use for the early upgrades (1993-1998) and an average of 10 percentage points for upgrades occurring during the more recent period (1999-2004). No estimates of uncertainty are provided. Calculations in the Appendix of Nichols et al. suggest that these estimates were based on simple pre- and 2-year post-intervention data, without control for underlying secular trends, so it seems likely that they may be overestimates of the treatment effect if the proportion of fatalities wearing seat belts is generally increasing over time. Hedlund et al. [25], however, use ARIMA models to conduct interrupted time series analyses on each of 6 upgrades that happened between 2000 and 2004 (Michigan, New Jersey, Washington, Delaware, Illinois, and Tennessee) using monthly crash data from FARS for 1994-2005. Although these estimates do not include the use of an untreated control group, they are likely less biased than simple pre/post comparisons. We extracted the point estimates and standard errors for each estimate of the effect of upgrading on the risk difference in the proportion of fatalities wearing seat belts among front-seat occupants.

As for MVC fatality rates, we conducted a random effects meta-analysis on the 6 estimates of the impact of upgrading on the proportion of fatal occupants wearing seat belts. eFigure 3 shows the forest plot and the summary estimate. The summary estimate implies that upgrading to primary enforcement increases the proportion of fatal occupants wearing seat belts by 13 percentage point, with a $95 \%$ CI of 10 to 16 . 
However, there is evidence of heterogeneity in the study estimates $Q=21.18,(d f=5), p=0.001$. In particular the effects appear weaker for later studies. Hedlund et al. note in their report that the limited duration of post-intervention follow-up time may be a reason for the weaker effects in Illinois and Tennessee.

eFigure 3: Random effects meta-analysis (with 95\% prediction interval) of prior studies of upgrades to primary enforcement on the proportion of fatal occupants wearing seat belts.

Impact on the proportion of fatal occupants using seat belts

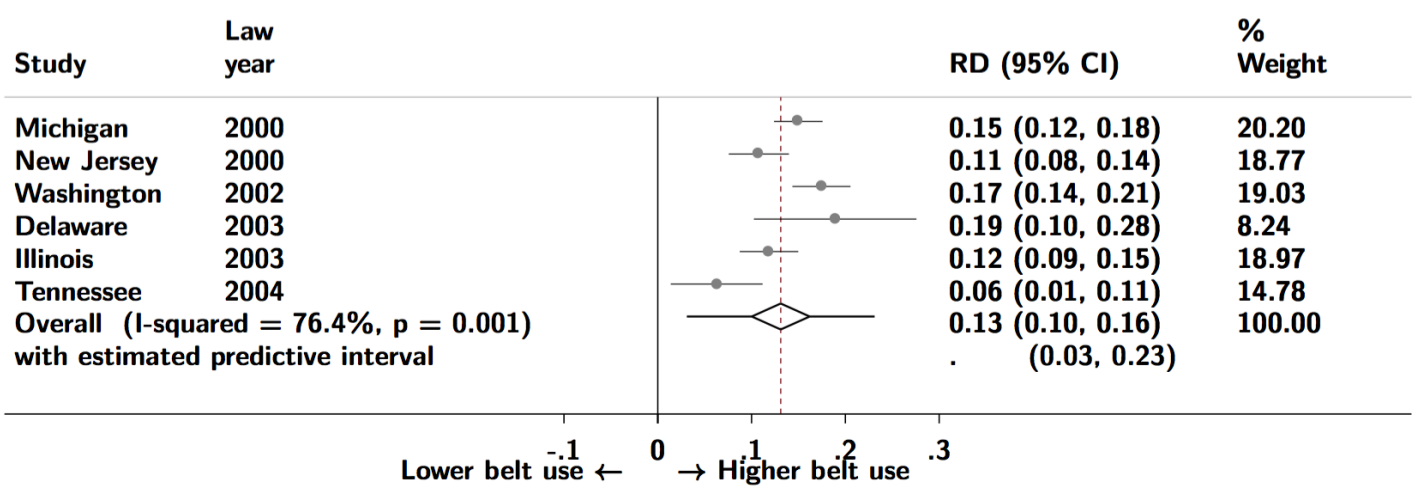


eTable 1: Date of mandatory seat belt laws and motor vehicle crash death rates 2000-2016.

\begin{tabular}{|c|c|c|c|c|}
\hline State & Secondary Law & Primary Law & $\begin{array}{c}\text { Rate per } 100,000 \\
\text { population }\end{array}$ & $\begin{array}{l}\text { Rate per billion vehicle } \\
\text { miles traveled }\end{array}$ \\
\hline Alabama & July 18,1992 & December 9, 1999 & 16.7 & 12.6 \\
\hline Alaska & September 12, 1990 & May 1, 2006 & 7.4 & 10.3 \\
\hline Arizona & January 1, 1991 & & 9.9 & 10.3 \\
\hline Arkansas & July 15, 1991 & June 30, 2009 & 15.5 & 13.6 \\
\hline California & January 1, 1986 & January 1, 1993 & 6.1 & 6.8 \\
\hline Colorado & July 1,1987 & & 8.1 & 8.4 \\
\hline Connecticut & & January 1, 1986 & 5.3 & 5.9 \\
\hline Delaware & January 1, 1992 & June 30, 2003 & 9.4 & 8.9 \\
\hline District of Columbia & December 12, 1985 & October 1, 1997 & 3 & 5 \\
\hline Florida & July 1,1986 & June 30, 2009 & 9.4 & 8.9 \\
\hline Georgia & September 1, 1988 & July 1, 1996 & 11.6 & 9.8 \\
\hline Hawaii & & February 16, 1985 & 4.7 & 6.3 \\
\hline Idaho & July 1,1986 & & 12.3 & 12 \\
\hline Illinois & January 1, 1988 & July 3, 2003 & 6.3 & 7.6 \\
\hline Indiana & July 1,1987 & July 1, 1998 & 8.3 & 7 \\
\hline lowa & & July 1,1986 & 9.9 & 9.5 \\
\hline Kansas & July 1, 1986 & June 10,2010 & 12 & 11.3 \\
\hline Kentucky & July 15, 1994 & July 20, 2006 & 14.9 & 13.4 \\
\hline Louisiana & July 1,1986 & September 1, 1995 & 13.3 & 13.2 \\
\hline Maine & December 27, 1995 & September 20, 2007 & 9.9 & 8.9 \\
\hline Maryland & July 1,1986 & October 1, 1997 & 6.5 & 6.6 \\
\hline Massachusetts & February 1, 1994 & & 3.9 & 4.6 \\
\hline Michigan & July 1,1985 & April 1, 2000 & 7.5 & 7.5 \\
\hline Minnesota & August 1, 1986 & June 9, 2009 & 6.9 & 6.4 \\
\hline Mississippi & July 1,1994 & May 27, 2006 & 21.8 & 16.1 \\
\hline Missouri & September 28, 1985 & & 13.1 & 11.1 \\
\hline Montana & October 1,1987 & & 18.6 & 15.9 \\
\hline Nebraska & January 1, 1993 & & 11 & 10.3 \\
\hline Nevada & July 1,1987 & & 8.1 & 9.4 \\
\hline \multicolumn{5}{|l|}{ New Hampshire } \\
\hline New Jersey & March 1, 1985 & May 1,2000 & 4.6 & 5.5 \\
\hline New Mexico & & January 1, 1986 & 14.1 & 11.2 \\
\hline New York & & December 1, 1984 & 3.8 & 5.6 \\
\hline North Carolina & & October 1, 1985 & 11.1 & 10 \\
\hline North Dakota & July 14, 1994 & & 13.9 & 11 \\
\hline Ohio & May 6, 1986 & & 7.5 & 7.8 \\
\hline Oklahoma & February 1, 1987 & November 1, 1997 & 14.7 & 11.5 \\
\hline Oregon & & December 7, 1990 & 7.9 & 8.6 \\
\hline Pennsylvania & November 23, 1987 & & 7.8 & 9.5 \\
\hline Rhode Island & June 18, 1991 & June 30, 2011 & 4.5 & 5.8 \\
\hline South Carolina & July 1,1989 & December 9, 2005 & 15.5 & 14.1 \\
\hline South Dakota & January 1, 1995 & & 14.5 & 13.1 \\
\hline Tennessee & April 21, 1986 & January 1, 2004 & 14 & 12.2 \\
\hline Texas & & September 1, 1985 & 10.2 & 10.5 \\
\hline Utah & April 28, 1986 & May 12, 2015 & 7.4 & 7.5 \\
\hline Vermont & January 1, 1994 & & 8.7 & 7.2 \\
\hline Virginia & January 1, 1988 & & 8.2 & 8 \\
\hline Washington & June 11, 1986 & July 1, 2002 & 5.8 & 6.8 \\
\hline West Virginia & September 1, 1993 & July 1, 2013 & 15.1 & 13.9 \\
\hline Wisconsin & December 1, 1987 & June 30, 2009 & 8.9 & 8.4 \\
\hline Wyoming & June 8, 1989 & & 21.6 & 12.7 \\
\hline
\end{tabular}




\section{Visualization of prior, likelihood, and posterior for motor vehicle crash deaths}

eFigure 4: Prior, likelihood, and posterior distributions of the effect of upgrading to primary enforcement on MVC fatality rates.

(a) Absolute effect

(a) Empirical prior $\left(\mu, \sigma^{2}\right)=(-0.5,0.44)$

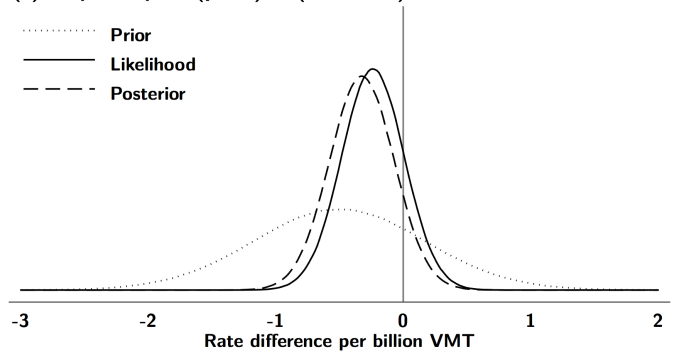

(b) Subjective prior $\left(\mu, \sigma^{2}\right)=(-1,0.5)$

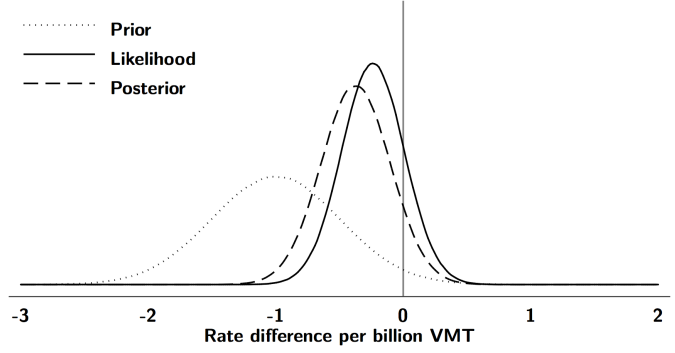

(b) Relative effect

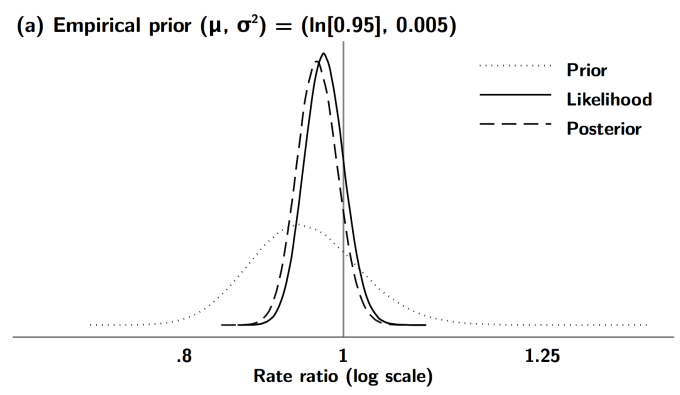

(b) Subjective rior $\left(\mu, \sigma^{2}\right)=(\ln [0.90], 0.003)$

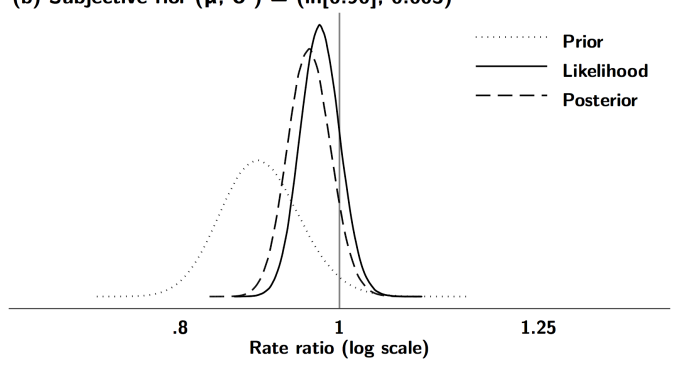




\section{Visualization of prior, likelihood, and posterior for proportion belted}

eFigure 5: Prior, likelihood, and posterior distributions of the effect of upgrading to primary enforcement on the proportion of death wearing seat belts.

(a) Absolute effect

(a) Empirical prior $\left(\mu, \sigma^{2}\right)=(0.12,0.003)$

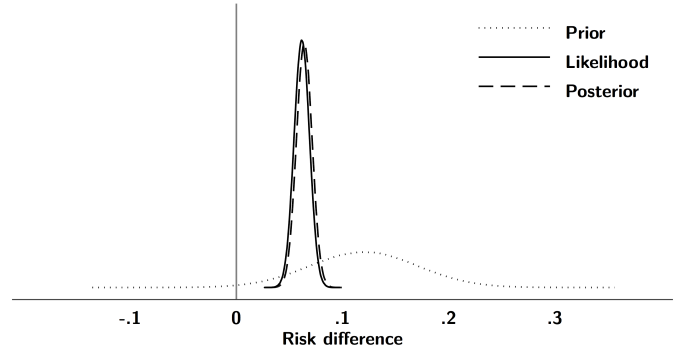

(b) Subjective prior $\left(\mu, \sigma^{2}\right)=(0.14,0.002)$

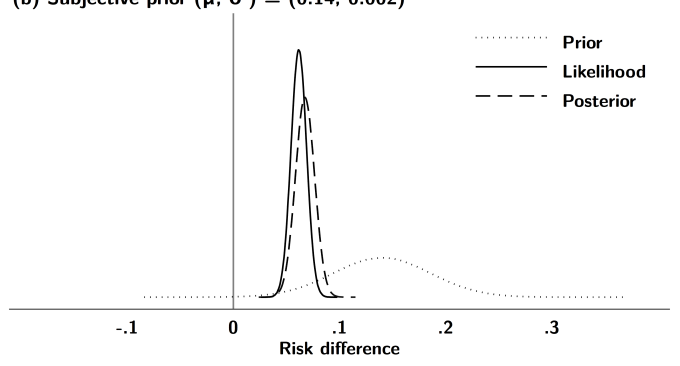

(b) Relative effect

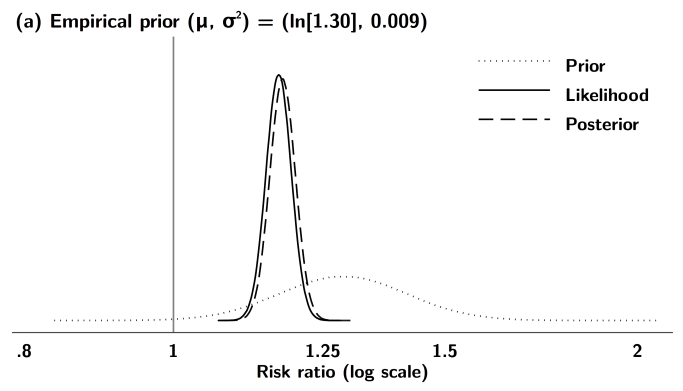

(b) Subjective prior $\left(\mu, \sigma^{2}\right)=(\ln [1.36], 0.007)$

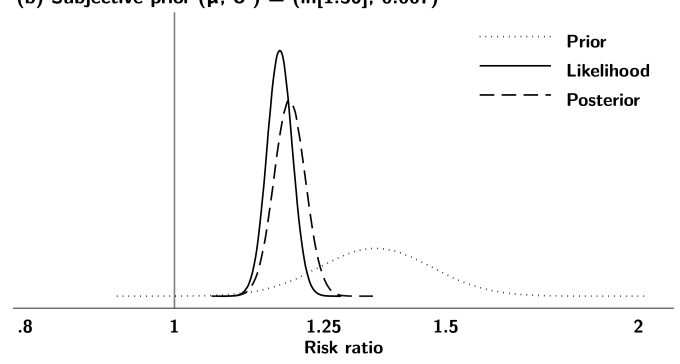




\section{Sensitivity analyses for motor vehicle crash deaths}

eTable 2: Sensitivity analysis using lagged exposure, alternative control groups, and temporal restriction for the effect of upgrading to primary enforcement of seat belt laws on motor vehicle crash death rates per billion VMT, US states, 2000-2016.

\begin{tabular}{lccccc}
\hline \hline & $\begin{array}{c}\text { Negative } \\
\text { binomial } \\
\text { regression }\end{array}$ & $\begin{array}{c}\text { Lagged policy } \\
\text { change by } \\
1 \text { year }\end{array}$ & $\begin{array}{c}\text { Secondary } \\
\text { enforcement only } \\
\text { as control group }\end{array}$ & $\begin{array}{c}\text { Primary } \\
\text { enforcement only } \\
\text { as control group }^{c}\end{array}$ & $\begin{array}{c}\text { Years prior } \\
\text { to Great } \\
\text { Recession }^{\text {d }}\end{array}$ \\
\hline Primary vs. secondary & & & & & \\
Rate difference & -0.12 & -0.18 & -0.37 & -0.58 & -0.04 \\
{$[-0.60,0.35]$} & {$[-0.66,0.30]$} & {$[-0.90,0.16]$} & {$[-1.11,-0.05]$} & {$[-0.63,0.55]$} \\
Rate ratio & 0.99 & 0.98 & 0.96 & 0.94 & 1.00 \\
\hline$N$ & {$[0.94,1.04]$} & {$[0.93,1.03]$} & {$[0.91,1.02]$} & {$[0.89,0.99]$} & {$[0.95,1.05]$} \\
\hline \hline
\end{tabular}

Note: All models used VMT (billions) as offset and subjective log-RR prior as $\mathrm{N}(\ln (0.90), 0.003)$. Except for negative binomial model all models were Poisson. Standard errors clustered by state. $95 \%$ posterior limits in brackets. Adjusted for age group, presence or absence of speed limit laws $(\leq 65,70,>70)$, graduated driver's license laws (night restrictions, passenger restrictions), maximum blood alcohol content laws $(0.08,0.10 \mathrm{~g} / \mathrm{dl})$, alcohol consumption per capita, police officers per capita, state median income, and state and year fixed effects. a Date of change from secondary to primary enforcement lagged by 1 year. ${ }^{b}$ Excluded states that had already upgraded to primary enforcement by 2001. ' Excluded states that maintained secondary primary enforcement through 2014.

d Using 2000-2007 data only (Great Recession began in December of 2007).

\section{Sensitivity analyses for proportion of deaths belted}

eTable 3: Sensitivity analysis using lagged exposure, alternative control groups, and temporal restriction for the effect of upgrading to primary enforcement of seat belt laws on the proportion of crash deaths wearing seat belts, US states, 2000-2016.

\begin{tabular}{|c|c|c|c|c|}
\hline & 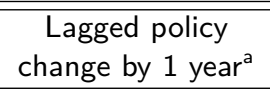 & $\begin{array}{l}\text { Secondary enforcement } \\
\text { only as control group }\end{array}$ & $\begin{array}{l}\text { Primary enforcement } \\
\text { only as control group }\end{array}$ & $\begin{array}{c}\text { Years prior to } \\
\text { Great Recession }^{\mathrm{d}}\end{array}$ \\
\hline \multicolumn{5}{|c|}{ Primary vs. secondary } \\
\hline Rate difference & $\begin{array}{c}0.06 \\
{[0.04,0.07]}\end{array}$ & $\begin{array}{c}0.07 \\
{[0.05,0.08]}\end{array}$ & $\begin{array}{c}0.07 \\
{[0.05,0.09]}\end{array}$ & $\begin{array}{c}0.04 \\
{[0.02,0.06]}\end{array}$ \\
\hline Rate ratio & $\begin{array}{c}1.16 \\
{[1.12,1.20]}\end{array}$ & $\begin{array}{c}1.18 \\
{[1.13,1.24]}\end{array}$ & $\begin{array}{c}1.18 \\
{[1.12,1.24]}\end{array}$ & $\begin{array}{c}1.12 \\
{[1.07,1.17]}\end{array}$ \\
\hline$N$ & 8000 & 8501 & 5951 & 4000 \\
\hline \multicolumn{5}{|c|}{$\begin{array}{l}\text { Note: Grouped logistic regression. Standard errors clustered by state. } 95 \% \text { posterior limits in brackets. Adjusted for age group, } \\
\text { presence or absence of speed limit laws }(\leq 65,70,>70) \text {, graduated driver's license laws (night restrictions, passenger restrictions), } \\
\text { maximum blood alcohol content laws }(0.08,0.10 \mathrm{~g} / \mathrm{dl}) \text {, alcohol consumption per capita, police officers per capita, state median } \\
\text { income, and state and year fixed effects. a Date of change from secondary to primary enforcement lagged by } 1 \text { year. b Excluded } \\
\text { states that had already upgraded to primary enforcement by } 2001 \text {. ' Excluded states that maintained secondary primary enforcement } \\
\text { through 2014. ' Using 2000-2007 data only (Great Recession began in December of 2007). }\end{array}$} \\
\hline
\end{tabular}




\section{Comparison with fully-Bayesian analysis}

In this paper we used a semi-Bayesian data augmentation approach. As we noted in the manuscript our chief reason for adopting a semi-Bayesian approach was our interest only in the policy parameter. We were not particularly interested in the parameters on, say, year terms, fixed state intercepts, or the covariates. The non-policy parameters are necessary parts of our identification strategy, but we did not see great value in specifying priors for these other parameters, particularly given a large sample size. The rationale for using data augmentation approach rather than a fully-Bayesian approach was that it would allow us to use cluster robust variance, which is standard in the program evaluation literature when treatments are assigned at the cluster (i.e., state) level [26].

We also thought a demonstration of the semi-Bayesian approach applied to a specific policy question could be useful for more applied researchers. This may be particularly useful from the perspective of conceptualizing prior evidence as data from an 'informationally equivalent' experiment with known results before our study. As Greenland and others have noted [27], although many researchers see the potential benefits of adopting a Bayesian approach, technical hurdles and the complexity of MCMC are likely barriers to adoption. In addition to our substantive interest in the question of stronger seat belt laws, we also thought it may be useful to demonstrate to readers how to quantitatively incorporate prior information without going "full Bayes". Data augmentation provides a mechanism for doing so that still allows researchers to utilize existing software for running analysis, provided the priors are specified with care and appropriately rescaled.

However, much of the literature on data augmentation approaches was developed prior to computational improvements for Bayesian analysis, so below we also include a table showing results from fully Bayesian analyses ( $\mathrm{R}$ code for models given below using the Bayesian Regression Models using Stan brms package) using default priors (a half Student- $t$ prior with $3 d f$, which has been shown to lead to better convergence than the traditional half Cauchy prior [28]), as well as a comparison with our semi-Bayesian analysis using subjective priors. The code we used to fit the model appears below, as well as some graphical evidence from the last model that the chains are well-mixed. From the table below it does not appear that the "fully Bayesian" model would provide substantially difference inference regarding the impact of the policy, which is perhaps not surprising since we have a lot of data that dominates the posterior. We do note that that fully Bayesian model tends to generate slightly more precise estimates relative to the semi-Bayes models fit using maximum likelihood with cluster robust standard errors (clustered by state), which are designed to be conservative in the case of clustered data. In both cases we would still interpret this as evidence of considerable weaker impacts relative to prior evidence and what is provided in existing policy documents, so we think that the fully Bayesian results support our overall conclusions.

eTable 4: Comparison of semi-Bayesian data augmentation and fully Bayesian models

\begin{tabular}{lccc}
\hline & \multicolumn{3}{c}{ Posterior estimates from Poisson } \\
\cline { 2 - 4 } Model & Mean & $95 \% \mathrm{LL}$ & $95 \%$ UL \\
\hline Non-informative priors for all parameters & & & \\
Semi-Bayes & -0.023 & -0.073 & 0.027 \\
Full Bayes* & -0.016 & -0.029 & -0.003 \\
$N(-1,0.05)$ for law, default priors for all others & & & \\
Semi-Bayes & -0.037 & -0.092 & 0.019 \\
Full Bayes* & -0.034 & -0.047 & -0.021 \\
\hline
\end{tabular}

\section{$R$ code for fully Bayesian models:}

\# Load reqired packages

library (haven) 


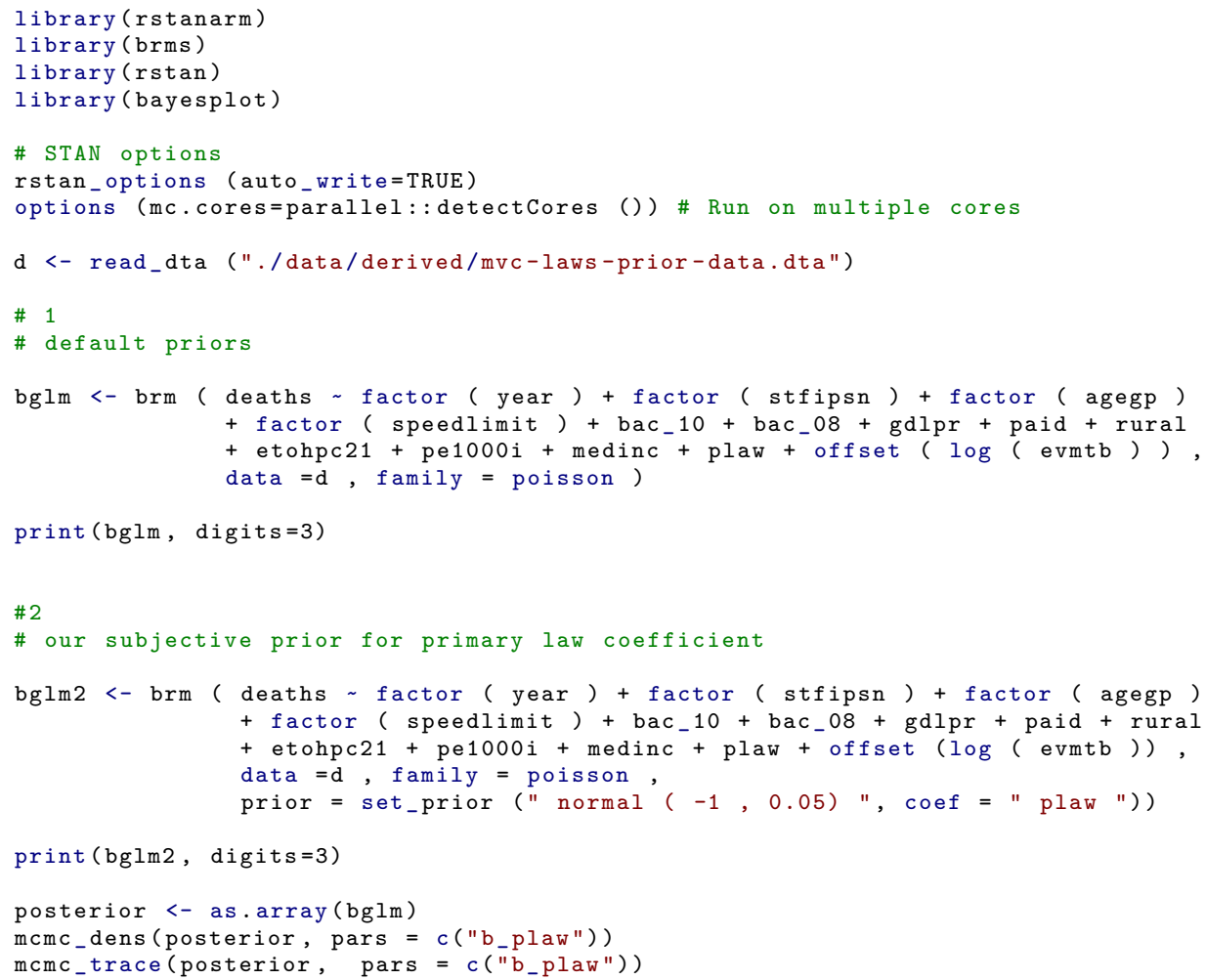

Density and trace plots for the plaw parameter from the fully Bayesian analysis with subjective prior for the plaw coefficient (model bglm2 above, 4 chains, each with iter $=2000$; warmup $=1000$; thin $=1$; total post-warmup samples $=4000)$ :
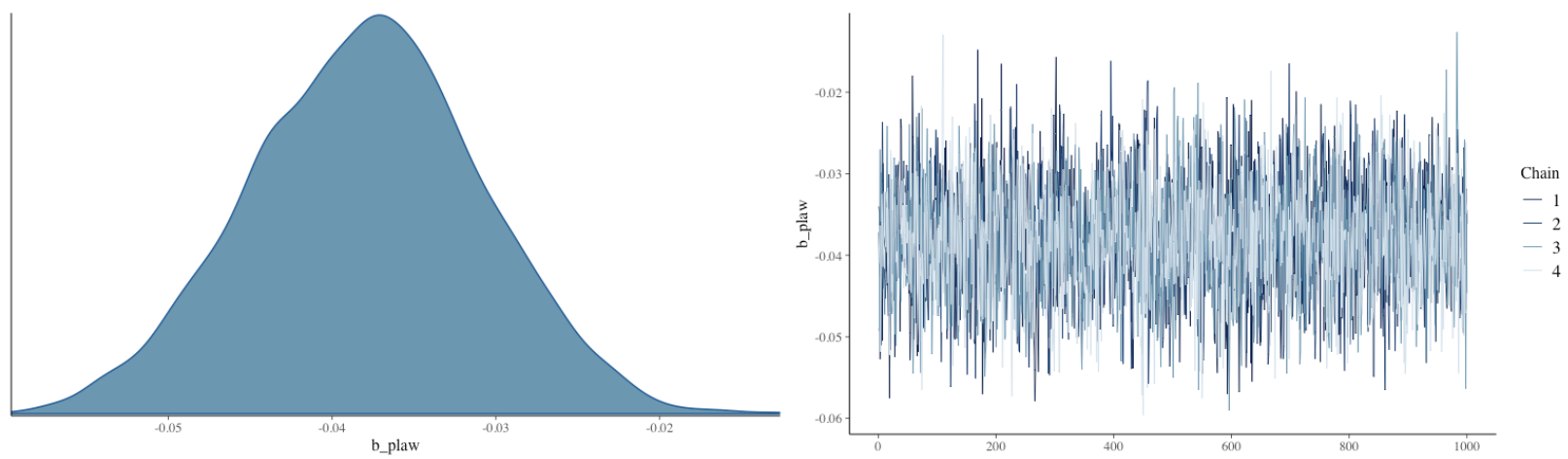


\section{Impact of alcohol-involved and rural road deaths}

The models below include different parameterizations of the annual proportion of alcohol-involved and rural road deaths. In our basic Poisson model for motor vehicle crash deaths including our coefficient of interest (primary law upgrade), state and year fixed effects, other time-varying state laws and covariates and log-billions of vehicle miles traveled as an offset, we ran 3 models: 1) without any adjustment for the annual state percentage of alcohol-involved and rural road deaths; 2) with both covariates measured the same year as the outcome; and 3) lagged 1 year. Stata code and results are given below.

\section{Stata code for sensitivity analysis:}

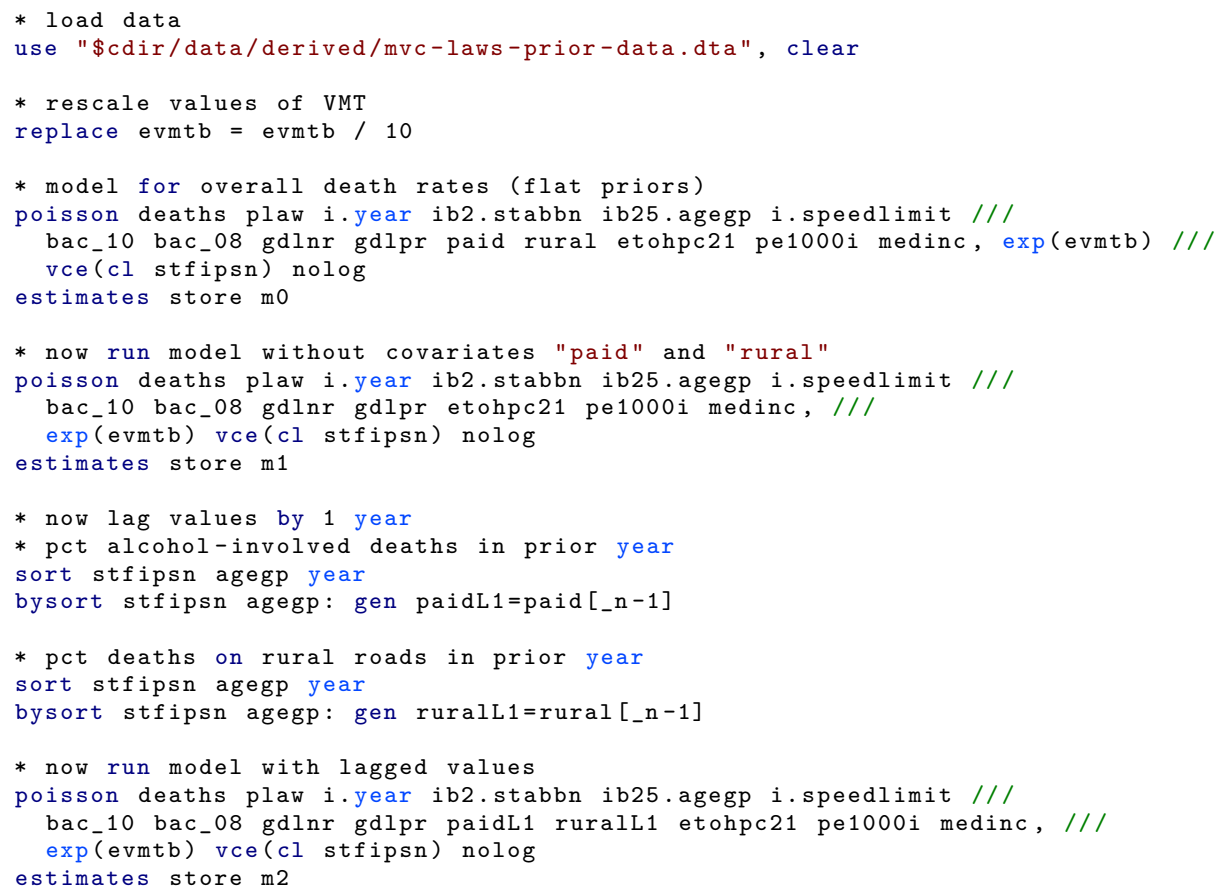

eTable 5: Different parameterizations of percentage of rural and alcohol-involved deaths as covariates

\begin{tabular}{lccc}
\hline \multirow{2}{*}{ Model } & \multicolumn{3}{c}{ Treatment of alcohol-involved and rural road deaths covariates } \\
\cline { 2 - 4 } & Included & Excluded & 1 year lagged values \\
\hline IRR for primary law & 0.98 & 0.97 & 0.99 \\
(95\% Cl for IRR) & $(0.93,1.03)$ & $(0.93,1.03)$ & $(0.94,1.04)$ \\
Observations & 8500 & 8500 & 8000 \\
\hline
\end{tabular}




\section{Frequentist regression estimates for motor vehicle crash deaths}

eTable 6: Frequentist difference-in-differences Poisson regression results for the effect of upgrading to primary enforcement of seat belt laws on motor vehicle crash death rates per billion VMT, US states, 20002016.

\begin{tabular}{|c|c|c|c|c|}
\hline & \multicolumn{2}{|c|}{ Coefficients } & \multicolumn{2}{|c|}{ Incidence Rate Ratios } \\
\hline & Coefficient & $95 \% \mathrm{Cl}$ & Coefficient & $95 \% \mathrm{Cl}$ \\
\hline Primary law upgrade & -0.025 & {$[-0.075,0.025]$} & 0.976 & {$[0.928,1.025]$} \\
\hline Per capita alcohol consumption & 0.165 & {$[0.001,0.330]$} & 1.180 & {$[1.001,1.391]$} \\
\hline Police employees per capita & 0.009 & {$[-0.003,0.020]$} & 1.009 & {$[0.997,1.020]$} \\
\hline Median income (10000s) & 0.037 & {$[-0.017,0.091]$} & 1.038 & {$[0.983,1.096]$} \\
\hline \multicolumn{5}{|l|}{ Max speed limit } \\
\hline Speed limit $<70 \mathrm{mph}$ & 0.000 & {$[0.000,0.000]$} & 1.000 & {$[1.000,1.000]$} \\
\hline Speed limit $70 \mathrm{mph}$ & 0.067 & {$[0.022,0.112]$} & 1.069 & {$[1.022,1.118]$} \\
\hline Speedlimit $>70 \mathrm{mph}$ & 0.187 & {$[0.042,0.332]$} & 1.206 & {$[1.043,1.394]$} \\
\hline \multicolumn{5}{|l|}{ BAC law } \\
\hline BAC 0.10 law & 0.011 & {$[-0.080,0.102]$} & 1.011 & {$[0.923,1.108]$} \\
\hline BAC 0.08 law & 0.013 & {$[-0.082,0.108]$} & 1.013 & {$[0.922,1.114]$} \\
\hline \multicolumn{5}{|l|}{ Graduated license law } \\
\hline GDL night restriction & 0.021 & {$[-0.042,0.083]$} & 1.021 & {$[0.959,1.087]$} \\
\hline GDL passenger restriction & -0.016 & {$[-0.067,0.034]$} & 0.984 & {$[0.935,1.035]$} \\
\hline \multicolumn{5}{|l|}{ Year of death } \\
\hline 2000 (ref) & 0.000 & {$[0.000,0.000]$} & 1.000 & {$[1.000,1.000]$} \\
\hline 2001 & -0.022 & {$[-0.053,0.010]$} & 0.978 & {$[0.948,1.010]$} \\
\hline 2002 & -0.014 & {$[-0.058,0.029]$} & 0.986 & {$[0.944,1.030]$} \\
\hline 2003 & -0.042 & {$[-0.096,0.012]$} & 0.959 & {$[0.909,1.012]$} \\
\hline 2004 & -0.082 & {$[-0.143,-0.020]$} & 0.922 & {$[0.867,0.980]$} \\
\hline 2005 & -0.102 & {$[-0.162,-0.041]$} & 0.903 & {$[0.850,0.960]$} \\
\hline 2006 & -0.147 & {$[-0.214,-0.080]$} & 0.863 & {$[0.807,0.923]$} \\
\hline 2007 & -0.212 & {$[-0.281,-0.143]$} & 0.809 & {$[0.755,0.867]$} \\
\hline 2008 & -0.319 & {$[-0.384,-0.254]$} & 0.727 & {$[0.681,0.776]$} \\
\hline 2009 & -0.388 & {$[-0.455,-0.320]$} & 0.679 & {$[0.634,0.726]$} \\
\hline 2010 & -0.437 & {$[-0.508,-0.367]$} & 0.646 & {$[0.602,0.693]$} \\
\hline 2011 & -0.468 & {$[-0.547,-0.389]$} & 0.626 & {$[0.579,0.678]$} \\
\hline 2012 & -0.452 & {$[-0.543,-0.362]$} & 0.636 & {$[0.581,0.697]$} \\
\hline 2013 & -0.493 & {$[-0.582,-0.403]$} & 0.611 & {$[0.559,0.668]$} \\
\hline 2014 & -0.508 & {$[-0.611,-0.405]$} & 0.602 & {$[0.543,0.667]$} \\
\hline 2015 & -0.479 & {$[-0.558,-0.400]$} & 0.620 & {$[0.573,0.671]$} \\
\hline 2016 & -0.472 & {$[-0.541,-0.402]$} & 0.624 & {$[0.582,0.669]$} \\
\hline \multicolumn{5}{|l|}{ Age group } \\
\hline $0-9 y$ & -1.878 & {$[-1.963,-1.793]$} & 0.153 & {$[0.140,0.166]$} \\
\hline $10-14 y$ & -2.435 & {$[-2.500,-2.369]$} & 0.088 & {$[0.082,0.094]$} \\
\hline $15-19 y$ & -0.323 & {$[-0.365,-0.281]$} & 0.724 & {$[0.694,0.755]$} \\
\hline $20-24 y$ & -0.165 & {$[-0.194,-0.136]$} & 0.848 & {$[0.824,0.873]$} \\
\hline $25-34 y$ (ref) & 0.000 & {$[0.000,0.000]$} & 1.000 & {$[1.000,1.000]$} \\
\hline $35-44 y$ & -0.237 & {$[-0.261,-0.213]$} & 0.789 & {$[0.770,0.808]$} \\
\hline $45-54 y$ & -0.325 & {$[-0.359,-0.291]$} & 0.723 & {$[0.699,0.748]$} \\
\hline $55-64 y$ & -0.591 & {$[-0.635,-0.548]$} & 0.554 & {$[0.530,0.578]$} \\
\hline $65-74 y$ & -0.845 & {$[-0.916,-0.773]$} & 0.430 & {$[0.400,0.461]$} \\
\hline $75+y$ & -0.525 & {$[-0.636,-0.414]$} & 0.592 & {$[0.530,0.661]$} \\
\hline$N$ & 8500 & & 8500 & \\
\hline
\end{tabular}

Note: Poisson regression with estimated vehicle miles traveled (billions) as offset. Standard errors clustered by state. $95 \%$ confidence intervalin brackets. State fixed effects not shown. 


\section{Frequentist regression estimates for proportion belted}

eTable 7: Frequentist difference-in-differences grouped logistic regression results for the effect of upgrading to primary enforcement of seat belt laws on the proportion of crash deaths wearing seat belts, US states, 2000-2016.

\begin{tabular}{|c|c|c|c|c|}
\hline & \multicolumn{2}{|c|}{ Coefficients } & \multicolumn{2}{|c|}{ Incidence Rate Ratios } \\
\hline & Coefficient & $95 \% \mathrm{Cl}$ & Coefficient & $95 \% \mathrm{Cl}$ \\
\hline Primary law upgrade & 0.277 & {$[0.213,0.342]$} & 1.320 & {$[1.237,1.407]$} \\
\hline Per capita alcohol consumption & -0.065 & {$[-0.231,0.100]$} & 0.937 & {$[0.794,1.106]$} \\
\hline Police employees per capita & 0.005 & {$[-0.009,0.019]$} & 1.005 & {$[0.991,1.020]$} \\
\hline Median income (10000s) & -0.018 & {$[-0.078,0.043]$} & 0.983 & {$[0.925,1.044]$} \\
\hline \multicolumn{5}{|l|}{ Max speed limit } \\
\hline Speed limit $<70 \mathrm{mph}$ & 0.000 & {$[0.000,0.000]$} & 1.000 & {$[1.000,1.000]$} \\
\hline Speed limit $70 \mathrm{mph}$ & 0.113 & {$[0.052,0.174]$} & 1.119 & {$[1.053,1.190]$} \\
\hline Speedlimit $>70 \mathrm{mph}$ & 0.247 & {$[0.076,0.418]$} & 1.280 & {$[1.079,1.519]$} \\
\hline \multicolumn{5}{|l|}{ BAC law } \\
\hline BAC 0.10 law & -0.027 & {$[-0.284,0.230]$} & 0.973 & {$[0.753,1.259]$} \\
\hline BAC 0.08 law & -0.086 & {$[-0.346,0.173]$} & 0.917 & {$[0.708,1.189]$} \\
\hline \multicolumn{5}{|l|}{ Graduated license law } \\
\hline GDL night restriction & -0.037 & {$[-0.105,0.031]$} & 0.964 & {$[0.901,1.031]$} \\
\hline GDL passenger restriction & -0.051 & {$[-0.122,0.020]$} & 0.950 & {$[0.885,1.021]$} \\
\hline \multicolumn{5}{|l|}{ Year of death } \\
\hline 2000 (ref) & 0.000 & {$[0.000,0.000]$} & 1.000 & {$[1.000,1.000]$} \\
\hline 2001 & 0.031 & {$[-0.022,0.083]$} & 1.031 & {$[0.978,1.087]$} \\
\hline 2002 & 0.105 & {$[0.061,0.150]$} & 1.111 & {$[1.062,1.162]$} \\
\hline 2003 & 0.183 & {$[0.127,0.239]$} & 1.201 & {$[1.136,1.270]$} \\
\hline 2004 & 0.255 & {$[0.204,0.305]$} & 1.290 & {$[1.226,1.357]$} \\
\hline 2005 & 0.253 & {$[0.177,0.329]$} & 1.287 & {$[1.193,1.389]$} \\
\hline 2006 & 0.252 & {$[0.160,0.345]$} & 1.287 & {$[1.174,1.411]$} \\
\hline 2007 & 0.283 & {$[0.198,0.369]$} & 1.328 & {$[1.219,1.446]$} \\
\hline 2008 & 0.269 & {$[0.167,0.370]$} & 1.308 & {$[1.182,1.448]$} \\
\hline 2009 & 0.289 & {$[0.165,0.414]$} & 1.336 & {$[1.180,1.512]$} \\
\hline 2010 & 0.322 & {$[0.197,0.447]$} & 1.380 & {$[1.218,1.563]$} \\
\hline 2011 & 0.311 & {$[0.171,0.450]$} & 1.364 & {$[1.187,1.568]$} \\
\hline 2012 & 0.327 & {$[0.173,0.481]$} & 1.387 & {$[1.189,1.618]$} \\
\hline 2013 & 0.376 & {$[0.231,0.521]$} & 1.457 & {$[1.260,1.684]$} \\
\hline 2014 & 0.417 & {$[0.269,0.565]$} & 1.518 & {$[1.309,1.760]$} \\
\hline 2015 & 0.418 & {$[0.304,0.531]$} & 1.518 & {$[1.356,1.700]$} \\
\hline 2016 & 0.414 & {$[0.283,0.545]$} & 1.513 & {$[1.328,1.725]$} \\
\hline \multicolumn{5}{|l|}{ Age group } \\
\hline $0-9 y$ & -0.515 & {$[-0.720,-0.311]$} & 0.597 & {$[0.487,0.733]$} \\
\hline $10-14 y$ & 0.210 & {$[0.098,0.321]$} & 1.233 & {$[1.103,1.379]$} \\
\hline $15-19 y$ & 0.174 & {$[0.136,0.212]$} & 1.190 & {$[1.146,1.236]$} \\
\hline $20-24 y$ & -0.002 & {$[-0.034,0.029]$} & 0.998 & {$[0.967,1.030]$} \\
\hline $25-34 y$ (ref) & 0.000 & {$[0.000,0.000]$} & 1.000 & {$[1.000,1.000]$} \\
\hline $35-44 y$ & 0.172 & {$[0.153,0.192]$} & 1.188 & {$[1.165,1.211]$} \\
\hline $45-54 y$ & 0.460 & {$[0.423,0.498]$} & 1.585 & {$[1.527,1.645]$} \\
\hline $55-64 y$ & 0.789 & {$[0.737,0.841]$} & 2.201 & {$[2.091,2.318]$} \\
\hline $65-74 y$ & 1.114 & {$[1.058,1.169]$} & 3.046 & {$[2.881,3.220]$} \\
\hline $75+y$ & 1.398 & {$[1.312,1.485]$} & 4.049 & {$[3.712,4.416]$} \\
\hline$N$ & 450006 & & 450006 & \\
\hline
\end{tabular}

Note: Grouped logistic regression with total number of deaths as denominator. Standard errors clustered by state. $95 \%$ confidence intervalin brackets. State fixed effects not shown. 


\section{References}

[1] National Highway Traffic Safety Administration. Primary Enforcement Saves Lives: The Case for Upgrading Secondary Safety Belt Laws. Report No DOT HS. 2006;810:649.

[2] Nichols JL, Ledingham KA. The impact of legislation, enforcement, and sanctions on safety belt use. vol. 601. Transportation Research Board; 2008.

[3] Ecola L, Batorsky B, Ringel JS. Using Cost-Effectiveness Analysis to Prioritize Spending on Traffic Safety. Rand Corporation; 2015.

[4] Goodwin A, Thomas L, Kirley B, Hall W, O'Brien N, Hill K. Countermeasures that work: A highway safety countermeasure guide for State highway safety offices, Eighth edition. National Highway Traffic Safety Administration; 2015.

[5] Sauber-Schatz EK, Ederer DJ, Dellinger AM, Baldwin GT. Vital Signs: Motor Vehicle Injury Prevention - United States and 19 Comparison Countries. MMWR Morb Mortal Wkly Rep. 2016;65(26):672-7.

[6] Wagenaar AC, Maybee RG, Sullivan KP. Mandatory seat belt laws in eight states: A time-series evaluation. J Safety Res. 1988;19(2):51-70.

[7] Evans WN, Graham JD. Risk reduction or risk compensation? The case of mandatory safety-belt use laws. J Risk Uncertainty. 1991;4(1):61-73.

[8] Houston DJ, Richardson Jr LE, Neeley GW. Legislating traffic safety: a pooled time series analysis. Soc Sci Quart. 1995;76(2).

[9] Houston DJ, Richardson LE, Neeley GW, et al. Mandatory Seat Belt Laws in the States A Study of Fatal and Severe Occupant Injuries. Eval Rev. 1996;20(2):146-159.

[10] Lee LK, Monuteaux MC, Burghardt LC, Fleegler EW, Nigrovic LE, Meehan WP, et al. Motor Vehicle Crash Fatalities in States With Primary Versus Secondary Seat Belt Laws: A Time-Series Analysis. Ann Intern Med. 2015 Aug;163(3):184-90.

[11] Dinh-Zarr TB, Sleet DA, Shults RA, Zaza S, Elder RW, Nichols JL, et al. Reviews of evidence regarding interventions to increase the use of safety belts. Am J Prev Med. 2001 Nov;21(4 Suppl):48-65.

[12] Shults RA, Nichols JL, Dinh-Zarr TB, Sleet DA, Elder RW. Effectiveness of primary enforcement safety belt laws and enhanced enforcement of safety belt laws: a summary of the Guide to Community Preventive Services systematic reviews. J Safety Res. 2004;35(2):189-96.

[13] Winnicki J. Safety belt use laws: evaluation of primary enforcement and other provisions. National Highway Traffic Safety Administration; 1995.

[14] Jonah B, Grant B. Long-term effectiveness of selective traffic enforcement programs for increasing seat belt use. J Appl Psychol. 1985 May;70:257-63.

[15] Farmer CM, Williams AF. Effect on fatality risk of changing from secondary to primary seat belt enforcement. J Safety Res. 2005;36(2):189-94.

[16] Salzberg P, Moffat J. Ninety five percent: an evaluation of law, policy, and programs to promote seat belt use in Washington state. J Safety Res. 2004;35:215-22.

[17] Voas RB, Fell JC, Tippetts AS, Blackman K, Nichols JL. Impact of primary safety belt laws on alcohol-related front-seat occupant fatalities: five case studies. Traffic Inj Prev. 2007 Sep;8(3):232-43.

[18] Shadish WR, Cook TD, Campbell DT. Experimental and quasi-experimental designs for generalized causal inference. Boston: Houghton Mifflin; 2001. 
[19] Meyer BD. Natural and Quasi-Experiments in Economics. J Bus Econ Stat. 1995;13(2):151-161.

[20] Angrist JD, Pischke JS. Mostly harmless econometrics: an empiricist's companion. Princeton Univ Press; 2008.

[21] Cohen A, Einav L. The effects of mandatory seat belt laws on driving behavior and traffic fatalities. Rev Econ Stat. 2003;85(4):828-843.

[22] Houston DJ, Richardson Jr LE. Reducing traffic fatalities in the American States by upgrading seat belt use laws to primary enforcement. J Policy Anal Manag. 2006;25(3):645-659.

[23] Borenstein M, Hedges LV, Higgins JPT, Rothstein HR. Introduction to meta-analysis. Chichester, U.K.: John Wiley \& Sons; 2009.

[24] Higgins JPT, Thompson SG. Quantifying heterogeneity in a meta-analysis. Stat Med. 2002 Jun;21(11):1539-58.

[25] Hedlund J, Gilbert SH, Ledingham KA, Preusser DF. How States Achieve High Seat Belt Use Rates. National Highway Traffic Safety Administration; 2008. DOT HS 810962.

[26] Cameron AC, Miller DL. A practitioner's guide to cluster-robust inference. J Hum Resour. $2015 ; 50(2): 317-372$.

[27] Greenland S. Bayesian perspectives for epidemiological research: I. Foundations and basic methods. Int J Epidemiol. 2006 Jun;35(3):765-75.

[28] Stan Development Team. Prior Choice Recommendations; 2018. Available from: https://github.com/stan-dev/stan/wiki/Prior-Choice-Recommendations [cited 2018-10-30]. 